\title{
Thermodynamic Study and Characterization by Electrochemical Technique of Pyrazole Derivatives as Corrosion Inhibitors for C38 Steel in Molar Hydrochloric Acid
}

\author{
I. El Ouali, ${ }^{a}$ A. Chetouani, ${ }^{a, b,{ }^{*}}$ B. Hammouti, ${ }^{a}$ A. Aouniti, ${ }^{a}$ R. Touzani,,${ }^{a, c}$ \\ S. El Kadiri ${ }^{a}$ and S. Nlate ${ }^{d}$ \\ ${ }^{a}$ LCAE-URAC18, Faculté des Sciences, Université Mohammed Premier; BP.717, 60 000, \\ Oujda Morocco \\ ${ }^{b}$ Laboratoire de Chimie Physique, Centre Régionale des Métiers de l'Education et de \\ Formation "CRMEF", de la Régionale Orientale, Morocco \\ ${ }^{c}$ Faculté Pluridisciplinaire Nador-Maroc. Faculté des Sciences, Oujda-Maroc. \\ ${ }^{d}$ Institut des Sciences Moléculaires, Université Bordeauxl-(UMR 5255 CNRS) - France
}

Received 25 November 2012; accepted 12 April 2013

\begin{abstract}
The effect of synthesized 1,1'-propane-1,3-diylbis[3-(chloromethyl)-5-methyl-1Hpyrazole], dimethyl 1,1'-butane-1,4-diylbis(5-methyl-1H-pyrazole-3-carboxylate) and 1,1'-butane-1,4-diylbis[3-(chloromethyl)-5-methyl-1H-pyrazole] on corrosion of C38 steel in hydrochloric acid solution has been investigated in the temperature range from $298 \mathrm{~K}$ to $328 \mathrm{~K}$ by weight loss, potentiodynamic polarization method and modelled with an equivalent electric circuit. All the compounds exhibited more than $90 \%$ anticorrosion activity, the highest is $96 \%$ by 1,1'-butane-1,4-diylbis[3-(chloromethyl)5-methyl-1H-pyrazole], and it has been shown that the inhibition efficiencies increased with the concentration of the inhibitors, remaining almost constant in a wide temperature range. Potentiodynamic polarization studies suggested that it is a predominance cathodic type. Nyquist plots showed depressed semicircles with their centre below the real axis. The adsorption on the C38 steel surface followed the Langmuir adsorption isotherm. The thermodynamic parameters for dissolution were investigated at different concentrations and temperature. The theoretical study by modelling the molecules of these inhibitors has been performed by considering the Density Functional Theory (DFT) using the Gaussian $03 \mathrm{~W}$ suite of programs that can calculate the different quantum parameters such as $\mathrm{E}_{\mathrm{HOMO}}, \mathrm{E}_{\mathrm{LUMO}} \Delta \mathrm{E}_{\mathrm{HOMO}}, \mathrm{E}_{\mathrm{LUMO}}$, and $\mu$ dipolar moment, allowing us to confirm the results found by the gravimetric and electrochemical methods.
\end{abstract}

Keywords: pyrazole, impedance spectroscopy, C38 steel, corrosion, equivalent electric circuit, potentiodynamic polarization, quantum theory.

\footnotetext{
* Corresponding author. E-mail address: ahmedchetouani70@ hotmail.com
} 


\section{Introduction}

Hydrochloric acid solutions are widely used for the pickling, cleaning, descaling and etching of mild steel [1-5]. Steel is widely used in various industries as structural materials. Its exposure to aggressive environments like concentrated acids, alkalis, salt solutions, etc., leads to its degradation. Inhibitors are often used to prevent metal dissolution as well as acid consumption [6-9]. Considerable quantities of corrosion loss of steel occurs in acid medium and inhibitors for carbon steel corrosion find importance among other corrosive media. Acid inhibitors have wide applications in the industrial field as a component in pre-treatment composition, in cleaning solution for industrial equipment and in acidulations of oil wells and in petrochemical plants.

The effect of organic compounds on the corrosion behaviour of metallic materials in aggressive solutions has been well documented 1,3-5,10-15]. It was found that the organic compounds are effective corrosion inhibitors due to their ability to form an adsorbed film on the metal surface. The efficiency of these organic corrosion inhibitors is related to the presence of polar functions with $\mathrm{S}, \mathrm{O}$ or $\mathrm{N}$ atoms in the molecule, heterocyclic groups and $\pi$-electrons [16-18].

At the majority of cases of these bipyrazolic compounds the mechanism action of inhibitors is of great importance and depends on their formulation as well as on their rational use in various environments. The electronic characteristic of the adsorbate molecules, the solution chemical composition, the nature of metallic surface, the temperature of the reaction, the immersion time and the electrochemical potential at the metal-solution interface determine the adsorption degree and hence the inhibition efficiency [7-9,17,19-22].

The corrosion inhibitors of steel are generally heterocyclic compounds. Some of these compounds have been synthesized for industrial, biological, and medicinal aims. Moreover, many N-heterocyclic compounds have been proved to be effective inhibitors in hydrochloric acid. Indeed, several triazoles [23-27], pyrazoles $[3,4,8,9,20,28]$, imidazoles [29,30], pyridazines [16,18,31], etc., have been among the best known and the most studied inhibitors. Notwithstanding several structural similarities with some of the above mentioned compounds, the tetrazol [32,33] and indoline derivatives [34-37] have been scarcely studied as steel corrosion inhibitors.

The use of bipyrazolic compounds and their derivatives as good inhibitors can be explained by the presence of atoms of nitrogen and oxygen in the molecule. These had a major effect on the inhibition efficiencies and consequently on the adsorption phenomenon on the metal surface, in addition to their large molecular surface which induces a widespread covering of the surface of the metal [7-9,16$18,21,22,38-43]$.

Other work in our laboratory, realized a correlation between experimental efficiencies of inhibitors and the results of quantum chemical calculations, and constructed a composite index of some of the key quantum chemical parameters in order to characterize the inhibition performance of the tested molecules. The quantum calculations tend to correlate the effect of structural parameters of 
substituted pyrazolic compounds to their inhibition efficiencies of corrosion of steel in $\mathrm{HCl}$ solution. Molecular orbital calculations are performed looking for good theoretical parameters to characterize the inhibition property of the inhibitors, which will be helpful to gain insight into the mechanism of corrosion inhibition and then to simulate the adsorption mode of the inhibitor on the metal surface. Also, from the calculations we will try to explain which adsorption site is favoured to bind to the metal surface.

The objective of the present work is to study the inhibitive action of 1,1'propane-1,3-diylbis[3-(chloromethyl)-5-methyl-1H-pyrazole] $\operatorname{Bip}(1)$, dimethyl 1,1'-butane-1,4-diylbis(5-methyl-1H-pyrazole-3-carboxylate) $\operatorname{Bip}(2)$ and 1,1'butane-1,4-diylbis[3-(chloromethyl)-5-methyl-1H-pyrazole] Bip(3) toward the corrosion of $\mathrm{C} 38$ steel in $1 \mathrm{M}$ hydrochloric acid solution. Weight loss, potentiodynamic polarization method and modelling with an equivalent electric circuit were used to evaluate the inhibition efficiency of Bip (1), Bip (2) and Bip (3). The efficiencies of corrosion inhibitors and the global chemical reactivity related to some parameters, such as highest occupied molecular orbital energy $\left(E_{\text {Номо }}\right)$, lowest unoccupied molecular orbital energy $\left(E_{L U M O}\right)$ and energy gap $(\triangle E)$, were calculated. All the calculations have been performed by considering the Density Functional Theory (DFT) using the GAUSSIAN03W suite of programs.

\section{Experimental}

\section{Inhibitors}

The compounds 1,1'-propane-1,3-diylbis[3-(chloromethyl)-5-methyl-1Hpyrazole] Bip(1), dimethyl 1,1'-butane-1,4-diylbis(5-methyl-1H-pyrazole-3carboxylate) $\mathrm{Bip}(2)$ and 1,1'-butane-1,4-diylbis[3-(chloromethyl)-5-methyl-1Hpyrazole] Bip(3), tested as corrosion inhibitors, characterised by NMR and IR techniques, are prepared according to the literature procedure involving three steps starting from the (5-Methyl-1H-pyrazole-3-carboxylic acid methyl ester) as starting material (Fig. 1).

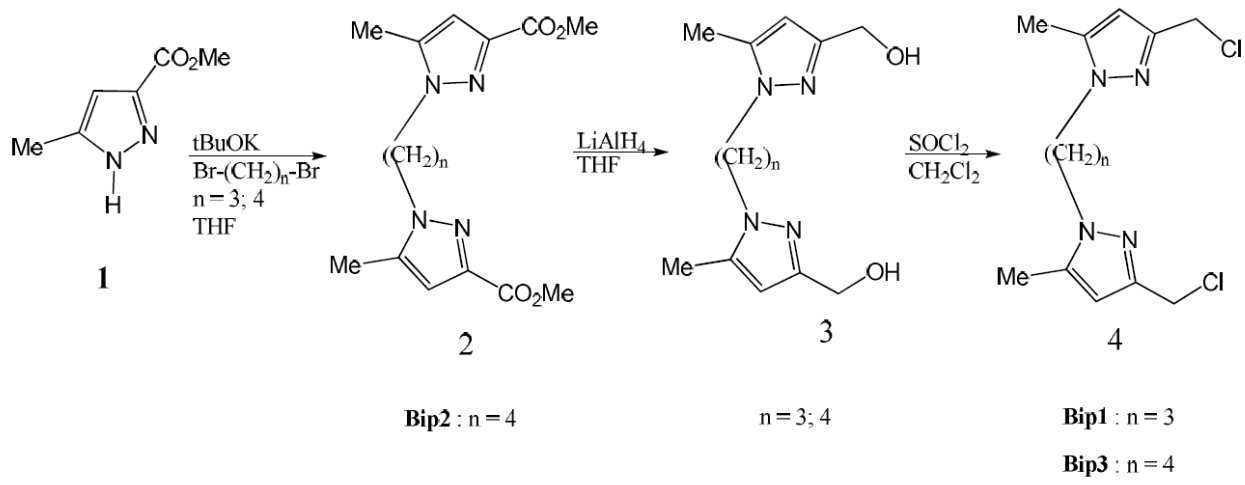

Figure 1. Synthesis reaction of Bip (1), Bip (2) and Bip (3) inhibitors.

This figure shows the operative method of synthesis: using 3-methoxycarbonyl5-methyl pyrazole (1) as precursor, 1,3-bis(3'-methoxy-carbonyl-5'-methyl-1'pyrazolyl) propane (2) was prepared in THF in the presence of t-BuOK by 
alkylation with 1,3-dibromopropane. The corresponding dialcohol (3) was obtained by a reduction of (2) with $\mathrm{LiAlH}$ according to the literature procedure [44] [44]. Chlorination was accomplished by dissolving the dialcohol (3) in $\mathrm{SOCl}_{2}$ and stirring the solution overnight at room temperature to give the dichlorinated derivative (4) in almost quantitative yield. The reactions are shown in the Fig. 1 and the molecular formula of the inhibitors is shown in Fig. 2.

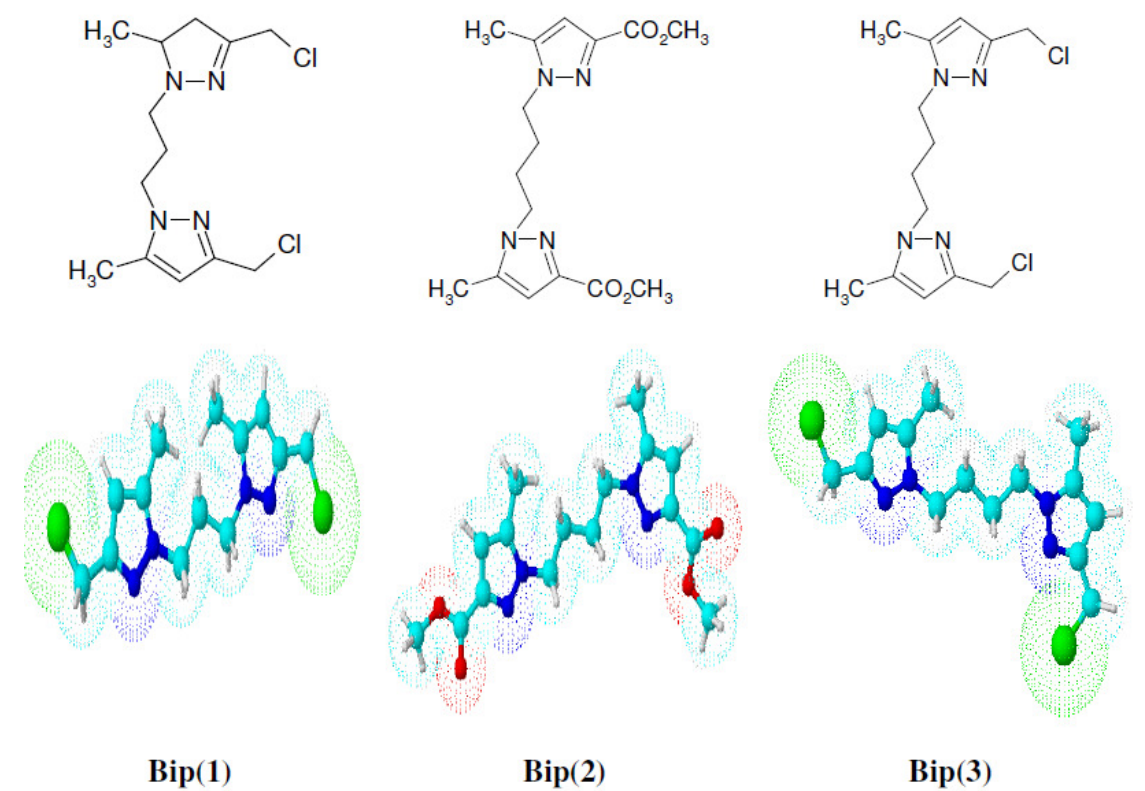

Figure 2. Structure of the different inhibitors $\operatorname{Bip}(1), \operatorname{Bip}(2)$ and $\operatorname{Bip}(3)$.

\section{Weight loss measurements}

The solution $1 \mathrm{M} \mathrm{HCl}$ was prepared by dilution of $37 \% \mathrm{HCl}$ analytical grade with double distilled water. The test solutions have been freshly prepared before each experiment by adding the oil directly to the corrosive solution. Each test run after de-aerated by bubbling nitrogen. Gas bubbling is maintained prior and through the experiments. Experiments were carried out in triplicate to ensure the reproducibility. Coupons used for weight loss measurements were cut into $(2 \times 2$ $\times 0.08) \mathrm{cm}^{3}$ dimensions, being the composition of C38 steel given in Table 1 .

Prior to all measurements, the exposed area was mechanically abraded with 180 , $320,800,1200$ grades of emery papers. The specimens were washed thoroughly with bidistilled water, degreased and dried with ethanol. Gravimetric measurements were carried out in a double walled glass cell equipped with a thermostated cooling condenser. The solution volume is $100 \mathrm{~cm}^{3}$. The immersion time for the weight loss is $6 \mathrm{~h}$ at $308 \mathrm{~K}$. Inhibition efficiency (IE \%) is calculated following equation 1 , where, $C_{R}$ and $C_{R}{ }^{0}$ are the corrosion rates of $C 38$ steel in the presence and absence of the organic compounds, respectively.

$$
E_{w}=100 \times\left(1-\frac{C_{R}}{C_{R}^{0}}\right)
$$


In order to investigate the effects of temperature on the inhibitor performance, some tests were carried out in a temperature range $313-353 \mathrm{~K}$ with $1 \mathrm{~h}$ immersion time for the weight loss.

Table 1. Chemical composition of C38 steel.

\begin{tabular}{|c|c|c|c|c|c|}
\hline$\% \mathrm{C}$ & $\% \mathrm{Si}$ & $\% \mathrm{Mn}$ & $\% \mathrm{~S}$ & $\% \mathrm{Cu}$ & $\% \mathrm{Fe}$ \\
\hline 0.179 & 0.165 & 0.439 & 0.203 & 0.034 & Balance \\
\hline
\end{tabular}

\section{Electrochemical tests}

The electrochemical study was carried out using a potentiostat PGZ100 piloted by Volta master software. This potentiostat is connected to a cell with three electrode thermostats with double wall (Tacussel Standard CEC/TH). A saturated calomel electrode (SCE) and a platinum electrode were used as reference and auxiliary electrodes, respectively. The material used for constructing the working electrode was the same used for gravimetric measurements. The surface area exposed to the electrolyte is $1 \mathrm{~cm}^{2}$.

Potentiodynamic polarization curves were plotted at a polarization scan rate of 1 $\mathrm{mV} / \mathrm{s}$. Before all experiments, the potential was stabilized at free potential during $30 \mathrm{~min}$. The polarisation curves are obtained from $-800 \mathrm{mV}$ to $-200 \mathrm{mV}$ at 308 $\mathrm{K}$. The solution test has been achieved after de-aerated by bubbling nitrogen. Gas bubbling is maintained prior and through the experiments. The data in Tafel region have been processed for evaluating the corrosion kinetic parameters by plotting the polarization curves. In a large domain of the potential, the linear Tafel segments of the cathodic curves were extrapolated to the corresponding corrosion potentials to obtain the corrosion current values. The inhibition efficiency was evaluated using the relationship (2), where $i_{\text {corr }}^{0}$ and $i_{\text {corr }}$ are the corrosion current density values without and with inhibitors, respectively.

$$
I E_{I-E}=\frac{i_{c o r r}^{0}-i_{c o r r}}{i_{\text {corr }}^{0}} \times 100
$$

The values of the degree of surface coverage $(\theta)$ have been obtained from polarization curves for various concentrations of the inhibitors. Here, $\theta$ can be given by equation 3 .

$$
\theta=1-\frac{i_{\text {corr }}}{i_{\text {corr }}^{0}}
$$

The electrochemical impedance spectroscopy (EIS) is a reliable and powerful technique to study the electric properties of the electrochemical systems. It is widely spread in various fields of research such as corrosion [1,5,45-47], characterization of the thin layers, and kinetics of electrode and batteries $[3,4,14,48-50]$. The principle of the realized electrochemical sensor bases on the measure of the impedance of an electrochemical cell by the technique of spectroscopy of impedance. This technique allows controlling the process of charges transfer in the interface electrode / electrolyte. Practically, the measure of 
the impedance is made in a three electrodes cell: an indicator electrode, a reference electrode and an auxiliary electrode (scheme 1). Indeed, a potential imposed with a sinusoidal disturbance of low amplitude, between the reference electrode and the indicator electrode, allows the measure of a current, of the same shape, generated between the indicator electrode and the auxiliary electrode. The report of the tension applied to the strength of moderate current defines the impedance of the electrochemical system. This impedance can be represented by an equivalent electric circuit according to the type of the system (faradic or not faradic system). In the case of faradic impedance, the surface of the electrode is partially or completely covered by a not insulating layer, or partially covered by an insulating layer capable of reacting with the redox couple, existing in the solution of measure. In that case, the moderate parameter is the resistance of transfer of charges; the impedimentary sensors show a sensibility more raised to the interaction of the ions. However, the redox species can have an effect on the stability and activity of the assembled electrode [51,52].

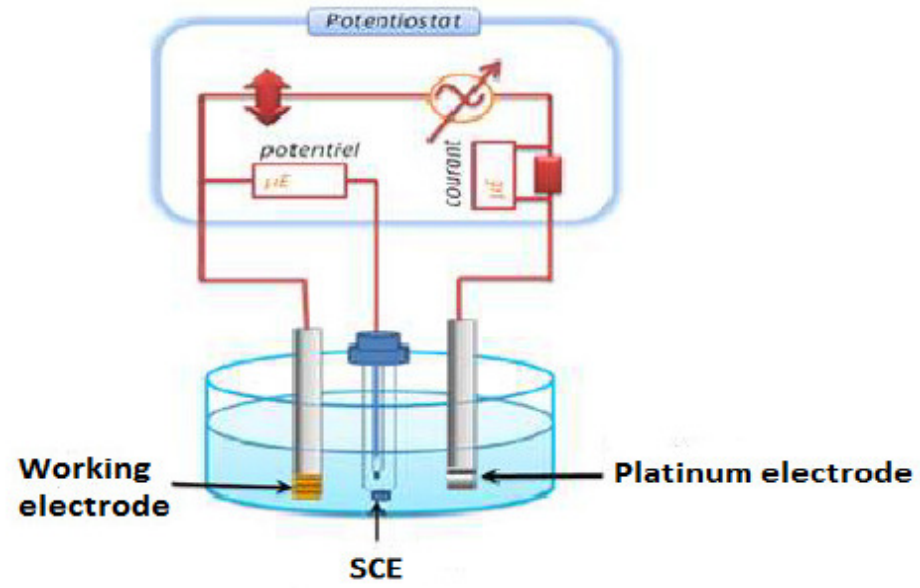

Scheme 1. Electrochemical measuring cell.

The electrochemical impedance spectroscopy (EIS) measurements are carried out with an electrochemical system (Tacussel), which included a digital potentiostat model Volta lab PGZ100 computer at $\mathrm{E}_{\text {corr }}$ after immersion in solution without bubbling. After the determination of the steady-state current at a corrosion potential, sine wave voltages $(10 \mathrm{mV})$ peak to peak, at frequencies between 100 $\mathrm{kHz}$ and $10 \mathrm{mHz}$, are superimposed on the rest potential. Computer programs automatically controlled the measurements performed at rest potentials after 0.5 hour of exposure at $308 \mathrm{~K}$. The impedance diagrams are given in the Nyquist representation. Experiments are repeated three times to ensure the reproducibility. To determine the impedance parameters of the C38 steel specimens in acidic solution, the measured impedance data were analyzed using Zview program based upon an electric equivalent circuit $[21,53]$. The chargetransfer resistance $\left(R_{t}\right)$ values are calculated from the difference in impedance at lower and higher frequencies. The charge transfer-resistance $\left(R_{t}\right)$ values were calculated from the difference in impedance at low and high frequencies $[8,9,54-$ 56]. The double layer capacitance $\left(\mathrm{C}_{\mathrm{dl}}\right)$ was obtained at the frequency $\mathrm{fm}$ at 
which the imaginary component of the impedance is maximal $\left(\mathrm{Z}_{\mathrm{i}, \max }\right)$ by equation 4:

$$
\mathrm{Cdl}=\frac{1}{2 \pi \mathrm{fm} \cdot \mathrm{R}_{\mathrm{t}}}
$$

The inhibition efficiency of the inhibitors has been determined from equation 5 , where $R_{t}^{0}$ and $R_{t}$ are the charge transfer resistance values in the absence and in the presence of the inhibitors, respectively.

$$
I E_{\text {imp }} \%=\frac{R_{t}-R_{t}^{0}}{R_{t}} \times 100
$$

\section{Theory and computational details}

DFT (density functional theory) methods were used in this study. These methods have become very popular in recent years because they can reach exactitude similar to other methods in less time being less expensive from the computational point of view. In agreement with the DFT results, energy of the fundamental state of a poly-electronic system can be expressed through the total electronic density, and in fact, the use of electronic density instead of wave function for calculating the energy constitutes the fundamental base of DFT [33,57-60]. All calculations were done by Gaussian 03W software, using the B3LYP functional and a 6-31G* basis set. The B3LYP, a version of DFT method, uses Becke's three-parameter functional (B3) and includes a mixture of HF with DFT exchange terms associated with the gradient corrected correlation functional of Lee, Yang, and Parr (LYP). The geometry of all species under investigation was determined by optimizing all geometrical variables without any symmetry constraints. Frontier molecular orbital's (HOMO and LUMO) may be used to predict the adsorption centres of the inhibitor molecule [54,61-63].

\section{Results and discussions}

\section{Effect of concentration on the corrosion rate and inhibition efficiency}

The values of inhibition efficiency percentage $(\% \mathrm{IE})$ and corrosion rate $\left(\mathrm{C}_{\mathrm{R}}\right)$ obtained from weight loss method at different concentrations at $308 \mathrm{~K}$ after $6 \mathrm{~h}$ of immersion period are summarized in Table 2. It has been found that 1,1'propane-1,3-diylbis[3-(chloromethyl)-5-methyl-1H-pyrazole] $\operatorname{Bip}(1)$, dimethyl 1,1'-butane-1,4-diylbis(5-methyl-1H-pyrazole-3-carboxylate) $\operatorname{Bip}(2)$ and 1,1'butane-1,4-diylbis[3-(chloromethyl)-5-methyl-1H-pyrazole] $\operatorname{Bip}(3)$ compounds inhibit the corrosion of $\mathrm{C} 38$ steel in HCI solution, at all concentrations. It has also been observed that the corrosion rate decreased with the increase of the inhibitor concentration.

IE\% reaches a maximum of $94 \%, 89 \%$ and $96 \%$ at $10^{-3} \mathrm{~mol} / \mathrm{L}$ for Bip1, Bip2 and Bip3, respectively. The plausible mechanism for corrosion inhibition of C38 steel in $1 \mathrm{M} \mathrm{HCl}$ by different inhibitors may be explained on the basis of the 
adsorption behaviour. The adsorption of the inhibitory molecules on the metal surface is described in several research papers [26,64-66].

Table 2. Corrosion parameters obtained from weight loss measurements for C38 steel in $1 \mathrm{M} \mathrm{HCl}$ containing various concentrations of different inhibitors at $308 \mathrm{~K}$ after $6 \mathrm{~h}$ immersion.

\begin{tabular}{|c|c|c|c|}
\hline Inhibitors & Concentration (M) & $C_{R}\left(\mathrm{mg} \cdot \mathrm{cm}^{-2} \cdot \mathrm{h}^{-1}\right)$ & IE (\%) \\
\hline Blanc & 1 & 0.964 & - \\
\hline \multirow{6}{*}{ Bip1 } & $10^{-6}$ & 0.6146 & 36 \\
\hline & $10^{-5}$ & 0.4104 & 57 \\
\hline & $5 \times 10^{-5}$ & 0.1558 & 84 \\
\hline & $10^{-4}$ & 0.0952 & 90 \\
\hline & $5 \times 10^{-4}$ & 0.0649 & 93 \\
\hline & $10^{-3}$ & 0.0565 & 94 \\
\hline \multirow{6}{*}{ Bip2 } & $10^{-6}$ & 0.7312 & 24 \\
\hline & $10^{-5}$ & 0.5264 & 45 \\
\hline & $5 \times 10^{-5}$ & 0.2563 & 73 \\
\hline & $10^{-4}$ & 0.1983 & 79 \\
\hline & $5 \times 10^{-4}$ & 0.1357 & 86 \\
\hline & $10^{-3}$ & 0.1048 & 89 \\
\hline \multirow{6}{*}{ Bip3 } & $10^{-6}$ & 0.5857 & 39 \\
\hline & $10^{-5}$ & 0.3093 & 68 \\
\hline & $5 \times 10^{-5}$ & 0.1301 & 86 \\
\hline & $10^{-4}$ & 0.0788 & 92 \\
\hline & $5 \times 10^{-4}$ & 0.0458 & 95 \\
\hline & $10^{-3}$ & 0.0364 & 96 \\
\hline
\end{tabular}

The adsorption of the Bip (1), Bip (2) and Bip (3) molecules could occur due to the formation of links between the d-orbital of the iron atoms, involving the displacement of water molecules from the metal surface, and the lone electron pairs. It was shown that the protective properties of such compounds depend upon their ability to reduce corrosion rate and are enhanced at higher electron densities around the nitrogen atoms specially $[8,9,16,18,43]$.

\section{Influence of temperature}

Gravimetric measurements were taken also at various temperatures (313-353 K) without and with 1,1'-propane-1,3-diylbis[3-(chloromethyl)-5-methyl-1Hpyrazole] Bip(1), dimethyl 1,1'-butane-1,4-diylbis(5-methyl-1H-pyrazole-3carboxylate) $\operatorname{Bip}(2)$ and 1,1'-butane-1,4-diylbis[3-(chloromethyl)-5-methyl-1Hpyrazole] Bip(3), inhibitors, during a period of one hour and at different concentrations; the corresponding results are given in Table 3.

It is clear from Table 3 that the inhibition efficiencies increase with increasing the concentration and that the corrosion rate increases in absence and presence the different inhibitors, but rising the temperature in a domain (313-353 K), in the presence of the inhibitor at different concentration of $\operatorname{Bip}(1), \operatorname{Bip}(2)$ and 
$\operatorname{Bip}(3)$, the inhibition efficiencies are almost independent upon the temperature; in the presence of blank solution the increase was more pronounced with the rise of temperature.

Table 3. Variation of the inhibition efficiency according to the temperature.

\begin{tabular}{|c|c|c|c|c|c|c|c|}
\hline \multirow{2}{*}{$\begin{array}{c}\mathbf{T} \\
(\mathbf{K})\end{array}$} & \multirow{2}{*}{$\begin{array}{c}\mathbf{C} \\
(\mathbf{M})\end{array}$} & \multicolumn{2}{|l|}{ Bip1 } & \multicolumn{2}{|c|}{ Bip2 } & \multicolumn{2}{|l|}{ Bip3 } \\
\hline & & $\begin{array}{c}\mathrm{W} \\
\left(\mathbf{m g} \cdot \mathrm{cm}^{-2} \cdot \mathbf{h}^{-1}\right)\end{array}$ & $\begin{array}{c}E \\
(\%)\end{array}$ & $\begin{array}{c}\mathrm{W} \\
\left(\mathrm{mg} \cdot \mathrm{cm}^{-2} \cdot \mathrm{h}^{-1}\right)\end{array}$ & $\begin{array}{c}\mathbf{E} \\
(\%)\end{array}$ & $\begin{array}{c}\mathrm{W} \\
\left(\mathbf{m g} \cdot \mathrm{cm}^{-2} \cdot \mathrm{h}^{-1}\right)\end{array}$ & $\begin{array}{c}E \\
(\%)\end{array}$ \\
\hline \multirow{5}{*}{313} & Blank & 1.087 & - & 1.087 & - & 1.087 & - \\
\hline & $5 \times 10^{-5}$ & 0.1653 & 85 & 0.3226 & 70 & 0.1725 & 84 \\
\hline & $10^{-4}$ & 0.1182 & 89 & 0.2486 & 77 & 0.1103 & 90 \\
\hline & $5 \times 10^{-4}$ & 0.0854 & 92 & 0.1607 & 85 & 0.0734 & 93 \\
\hline & $10^{-3}$ & 0.0734 & 93 & 0.1182 & 89 & 0.0389 & 96 \\
\hline \multirow{5}{*}{323} & Blank & 2.823 & - & 2.823 & - & 2.823 & - \\
\hline & $5 \times 10^{-5}$ & 0.4481 & 84 & 0.8917 & 68 & 0.5046 & 82 \\
\hline & $10^{-4}$ & 0.3634 & 87 & 0.6703 & 76 & 0.3287 & 88 \\
\hline & $5 \times 10^{-4}$ & 0.2506 & 91 & 0.4887 & 83 & 0.2210 & 92 \\
\hline & $10^{-3}$ & 0.1904 & 93 & 0.3631 & 87 & 0.1314 & 95 \\
\hline \multirow{5}{*}{333} & Blank & 4.802 & - & 4.802 & - & 4.802 & - \\
\hline & $5 \times 10^{-5}$ & 1.0485 & 78 & 1.6459 & 66 & 0.9886 & 79 \\
\hline & $10^{-4}$ & 0.6663 & 86 & 1.2987 & 73 & 0.675 & 86 \\
\hline & $5 \times 10^{-4}$ & 0.5404 & 89 & 0.8103 & 83 & 0.4208 & 91 \\
\hline & $10^{-3}$ & 0.3781 & 92 & 0.7143 & 85 & 0.2806 & 94 \\
\hline \multirow{5}{*}{343} & Blank & 9.963 & - & 9.963 & - & 9.963 & - \\
\hline & $5 \times 10^{-5}$ & 2.4782 & 75 & 3.6627 & 63 & 2.3713 & 76 \\
\hline & $10^{-4}$ & 1.7991 & 82 & 2.8639 & 71 & 1.9238 & 81 \\
\hline & $5 \times 10^{-4}$ & 1.2541 & 87 & 1.9803 & 80 & 1.0482 & 89 \\
\hline & $10^{-3}$ & 1.1715 & 88 & 1.5988 & 84 & 0.716 & 93 \\
\hline \multirow{5}{*}{353} & Blank & 17.957 & - & 17.957 & - & 17.957 & - \\
\hline & $5 \times 10^{-5}$ & 4.9982 & 72 & 7.3319 & 59 & 4.7947 & 73 \\
\hline & $10^{-4}$ & 4.1328 & 77 & 5.8833 & 67 & 3.2018 & 82 \\
\hline & $5 \times 10^{-4}$ & 2.9288 & 84 & 4.2674 & 76 & 2.1633 & 88 \\
\hline & $10^{-3}$ & 2.4706 & 86 & 3.3694 & 81 & 1.5705 & 91 \\
\hline
\end{tabular}

We may conclude that 1,1'-propane-1,3-diylbis[3-(chloromethyl)-5-methyl-1Hpyrazole] $\operatorname{Bip}(1)$, dimethyl 1,1'-butane-1,4-diylbis(5-methyl-1H-pyrazole-3carboxylate) $\mathrm{Bip}(2)$ and 1,1'-butane-1,4-diylbis[3-(chloromethyl)-5-methyl-1Hpyrazole] $\mathrm{Bip}(3)$, are excellent inhibitors of $\mathrm{C} 38$ steel corrosion in $1 \mathrm{M} \mathrm{HCl}$ solution at high temperatures. E\% reaches around $90 \%$ at $10^{-3} \mathrm{M}$ at different temperatures for 1, 1'-butane-1, 4-diylbis [3-(chloromethyl)-5-methyl-1Hpyrazole] Bip (3).

Fig. 3 shows the Arrhenius plots for the corrosion rate for both the blank and the inhibitors solutions of Bip (1), Bip (2) and Bip (3). The Arrhenius plots for C38 steel corrosion rate were determined from the slopes of $\ln (\mathrm{W})$ versus $1000 / \mathrm{T}$ plots. Equation 6 can determine the apparent activation energies, where $\mathrm{E}_{\mathrm{a}}$ and $\mathrm{E}_{\mathrm{a}}$ ' are the apparent activation energies with and without inhibitors, respectively: 


$$
\log \left(W_{\text {corr }}\right)=\frac{-E_{a}}{R T}+A \text { and } \log \left(W_{\text {corr }}^{\prime}\right)=\frac{-E_{a}{ }^{\prime}}{R T}+A
$$
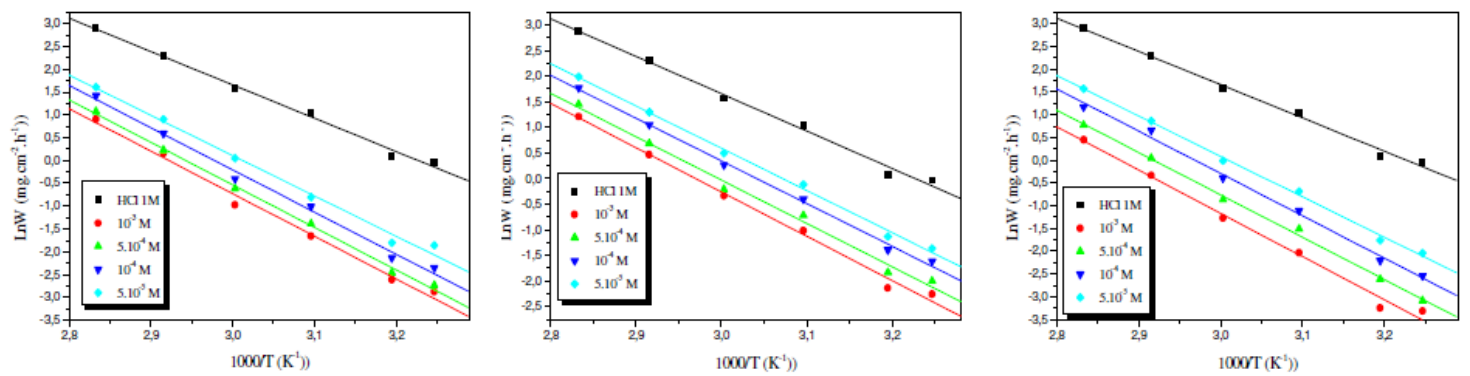

Figure 3. Arrhenius plots of the corrosion rate for both the blank and the inhibitors solutions.

It can be seen that the corrosion weight loss for C38 steel increases more rapidly with temperature in uninhibited solution than in inhibited solutions. This result confirms that the inhibitor acts as an efficient corrosion inhibitor in the range of temperature studied.

The evolved hydrogen is produced by reduction of hydrochloric acid at various temperatures $[9,55,56]$. Inhibitors protect the metal by adsorbing onto the surface. The inhibitor molecules are adsorbed to a different extent at different types of surface sites and influence the anodic and cathodic reactions unequally [65,67-70]. Much research in our laboratory concluded that the adsorption of inhibitor molecules reduces the number of electrode reaction sites and thus inhibition becomes more predominant when the surface is covered with nearly a monolayer of the inhibitor [7-9,16-18,22,43].

In 1,1'-propane-1,3-diylbis[3-(chloromethyl)-5-methyl-1H-pyrazole] Bip(1), dimethyl 1,1'-butane-1,4-diylbis(5-methyl-1H-pyrazole-3-carboxylate) $\operatorname{Bip}(2)$ and 1,1'-butane-1,4-diylbis[3-(chloromethyl)-5-methyl-1H-pyrazole] Bip(3) molecules, $\mathrm{N}$ and $\mathrm{O}$ atoms act as reaction centres leading to the formation of the film on the surface of the alloy. Bip (1), Bip (2) and Bip (3) are excellent inhibitors, having two polar atoms $\mathrm{N}$ and $\mathrm{O}$. The cyclic provides also a high electron density and it has been found that the inhibitor efficiency increases with the electron density.

An alternative formulation of Arrhenius equation is (7):

$$
W=\frac{R T}{N . h} \exp \left(\frac{\Delta S^{0}{ }_{a}}{R}\right) \exp \left(-\frac{\Delta H^{0}{ }_{a}}{R T}\right)
$$

where $h$ is Plank's constant, $N$ is Avogadro's number, $\Delta S_{a}{ }^{0}$ is the entropy of activation and $\Delta H_{a}{ }^{0}$ is the enthalpy of activation. Fig. 4 shows a plot of $\ln (W / T)$ against $1 / T$ in the absence and presence of the inhibitors. Straight lines are obtained with a slope of $\left(-\Delta H_{a}^{0} / R\right)$ and an intercept of $\left(\operatorname{Ln} R / N h+\Delta S_{a}^{0} / R\right)$ from which the values of $\Delta H_{a}{ }^{0}$ and $\Delta S_{a}{ }^{0}$ are calculated (Table 4). The relationship between the activation energy $E_{\mathrm{a}}$ and activation heat $\Delta H_{a}{ }^{0}$ against the concentration of the inhibitors is also lited in Table 4. From the data obtained in this Table, it seems that $E_{\mathrm{a}}$ and $\Delta H_{a}{ }^{0}$ vary in the same manner; these results agree 
with those obtained in the literature [16] and they allow the verification of the known thermodynamic reaction between the $E_{\mathrm{a}}$ and $\Delta H_{a}{ }^{0}$ :

$$
\Delta H_{\mathrm{a}}^{\circ}=E_{\mathrm{a}}-R T
$$

Moreover, $\Delta S_{\text {a }}^{\circ}$ values are more positive in $1 \mathrm{M} \mathrm{HCl}$ solutions containing the inhibitor than those obtained in the uninhibited solution. This observation is in agreement with the findings of other workers $[16,25,56]$.
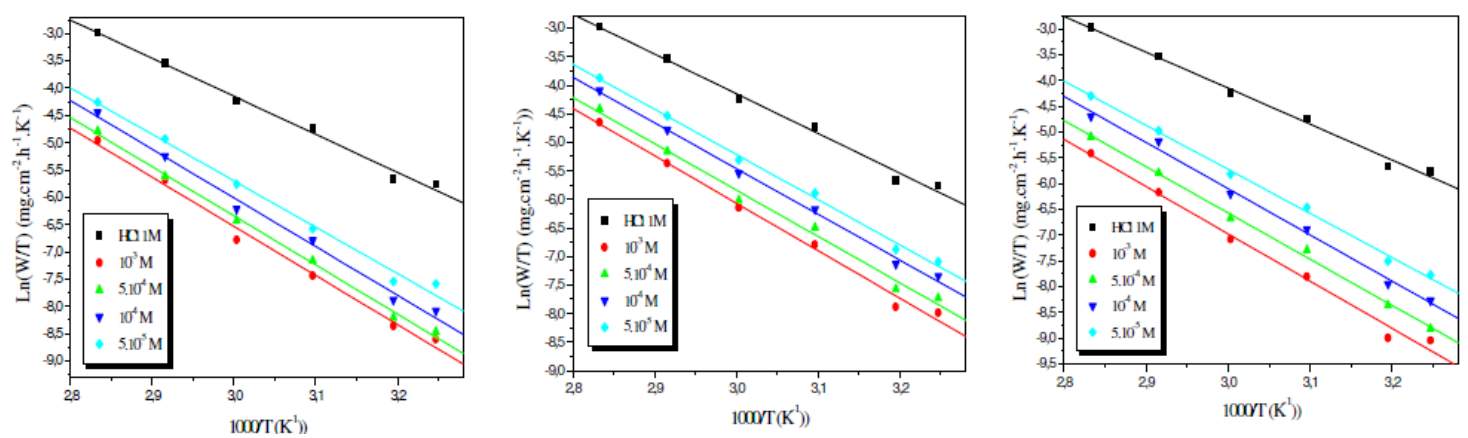

Figure 4. Plots of $\ln (\mathrm{W} / \mathrm{T})$ versus $1 / \mathrm{T}$ with and without Bip (1), Bip (2) and Bip (3) at different concentrations.

Table 4 presents the calculated values of $E_{a}, \Delta \mathrm{S}^{\circ}$ and $\Delta \mathrm{H}^{\circ}$ a in inhibited and uninhibited acid solutions. It is observed that the activation energy is higher in the presence of $\operatorname{Bip}(1), \operatorname{Bip}(2)$ and $\operatorname{Bip}(3)$ inhibitors than in their absence. The negative slope of $E_{a}$ indicates the adsorption of inhibitor compounds on the electrode surface [7-9,22,32,43].

Since the presence of the inhibitor causes a change almost of $15 \mathrm{~kJ} / \mathrm{mol}, 10$ $\mathrm{kJ} / \mathrm{mol}$ and $20 \mathrm{~kJ} / \mathrm{mol}$ for $\operatorname{Bip}(1), \operatorname{Bip}(2)$ and $\operatorname{Bip}(3)$ at $10^{-3} \mathrm{M}$, respectively, in the values of the apparent activation energy, thus it indicates a change in the rate determining step brought about by the presence of the various chemical components at different concentrations.

Table 4. Thermodynamic parameters at different concentrations.

\begin{tabular}{|c|c|c|c|c|c|c|c|c|c|}
\hline \multirow[b]{2}{*}{ Blank } & \multicolumn{3}{|c|}{ Ea $(\mathbf{k J} / \mathbf{m o l})$} & \multicolumn{3}{|c|}{$\Delta \mathrm{Ha}^{\circ}(\mathrm{kJ} / \mathrm{mol})$} & \multicolumn{3}{|c|}{$\Delta \mathrm{Sa}^{\circ}(\mathrm{J} / \mathrm{mol} . \mathrm{K})$} \\
\hline & \multicolumn{3}{|c|}{60.70} & \multicolumn{3}{|c|}{57.97} & \multicolumn{3}{|c|}{-58.33} \\
\hline \multirow[b]{2}{*}{$\mathrm{C}(\mathrm{M})$} & \multicolumn{3}{|c|}{ Bip1 } & \multicolumn{3}{|c|}{ Bip2 } & \multicolumn{3}{|c|}{ Bip3 } \\
\hline & $\begin{array}{c}\text { Ea } \\
(\mathbf{k J} / \mathbf{m o l})\end{array}$ & $\underset{(\mathbf{k J} / \mathbf{m o l})}{\Delta \mathbf{H a}^{\circ}}$ & $\underset{(\mathbf{J} / \mathbf{m o l} . \mathbf{K})}{\Delta \mathbf{S a}^{\circ}}$ & $\underset{(\mathbf{k J} / \mathbf{m o l})}{\mathbf{E a}}$ & $\underset{(\mathbf{k J} / \mathbf{m o l})}{\Delta \mathrm{Ha}^{\circ}}$ & $\underset{(\mathrm{J} / \mathbf{m o l} . \mathbf{K})}{\Delta \mathbf{S a}^{\circ}}$ & $\underset{(\mathbf{k J} / \mathbf{m o l})}{\mathbf{E a}}$ & $\underset{(\mathbf{k J} / \mathbf{m o l})}{\Delta \mathbf{H a}^{\circ}}$ & $\underset{(\mathbf{J} / \mathbf{m o l} . \mathbf{K})}{\Delta \mathbf{S a}^{\circ}}$ \\
\hline $5 \times 10^{-5}$ & 73.42 & 70.68 & -33.06 & 68.59 & 65.85 & -43.54 & 73.84 & 71.10 & -32.03 \\
\hline $10^{-4}$ & 76.85 & 74.11 & -25.41 & 69.36 & 66.63 & -43.26 & 77.29 & 74.56 & -24.77 \\
\hline $5 \times 10^{-4}$ & 77.49 & 74.75 & -26.20 & 70.33 & 67.60 & -43.48 & 77.31 & 74.57 & -28.64 \\
\hline $10^{-3}$ & 77.56 & 74.83 & -27.59 & 71.98 & 69.25 & -40.49 & 78.97 & 76.23 & -27.03 \\
\hline
\end{tabular}

This means that the adsorption process takes place easily and the adsorption layer on C38 steel is stable. The value of activation energy $\left(E_{a}\right)$ that has been found is greater than that in the uninhibited solution. While the higher value of the activation energy of the process in an inhibitor's presence when compared to that 
in its absence is attributed to its physical adsorption. The physical adsorption is a result of electrostatic attraction between the charged metal surface and the charged species in the bulk of the solution. Adsorption of negatively charged species is facilitated if the metal surface is positively charged. Positively charged species can also protect the positively charged metal surface acting with a negatively charged intermediate, such as acid anions adsorbed on the metal surface [21,24-26,37,41,71-73].

The values of $\Delta \mathrm{H}^{0}$ are reported in Table 4 . The heat of adsorption is known to be a good measure of the strength of adsorption on the surface. Thus, the positive sign of the enthalpy $\left(\Delta \mathrm{H}_{\mathrm{a}}^{0}\right)$ reflects the endothermic nature of the C38 steel dissolution process and its values vary in the same way with the inhibitor concentration in acid solutions.

On the other hand, values of $\Delta \mathrm{S}_{\mathrm{a}}^{0}$ are more positive in acid solutions containing inhibitors than those obtained in the uninhibited solutions. This behaviour can be explained as a result of the replacement process of water molecules during adsorption of inhibitors on C38 steel surface. This observation is in agreement with the findings of other workers [7-9,22,56,74-76]. However, C38 steel corrosion in the free acid was characterized by the more negative $\Delta S^{0}$ a value which implies that the activation complex in the rate determining step required association rather than dissociation $[8,9,21,41,56,74]$.

Inspection of these data in table 4 reveals that the $\Delta H^{0}{ }_{a}$ values for dissolution reaction of $\mathrm{C} 38$ steel in $1.0 \mathrm{M} \mathrm{HCl}$ in the presence of the inhibitor at different concentrations are higher than those in the absence of inhibitors. The positive signs of $\Delta H^{0}{ }_{\mathrm{a}}$ reflect the endothermic nature of the $\mathrm{C} 38$ steel dissolution process suggesting that the dissolution of $\mathrm{C} 38$ steel is slow in the presence of inhibitor.

\section{Potentiodynamic polarization measurements}

Polarization measurements were scrutinized in order to gain knowledge concerning the kinetics of the cathodic and anodic reactions. Fig. 5 shows cathodic and anodic polarization curves recorded for $\mathrm{C} 38$ steel in HCI solution in the absence and presence of various concentrations of $\operatorname{Bip}(1), \operatorname{Bip}(2)$ and $\operatorname{Bip}(3)$.
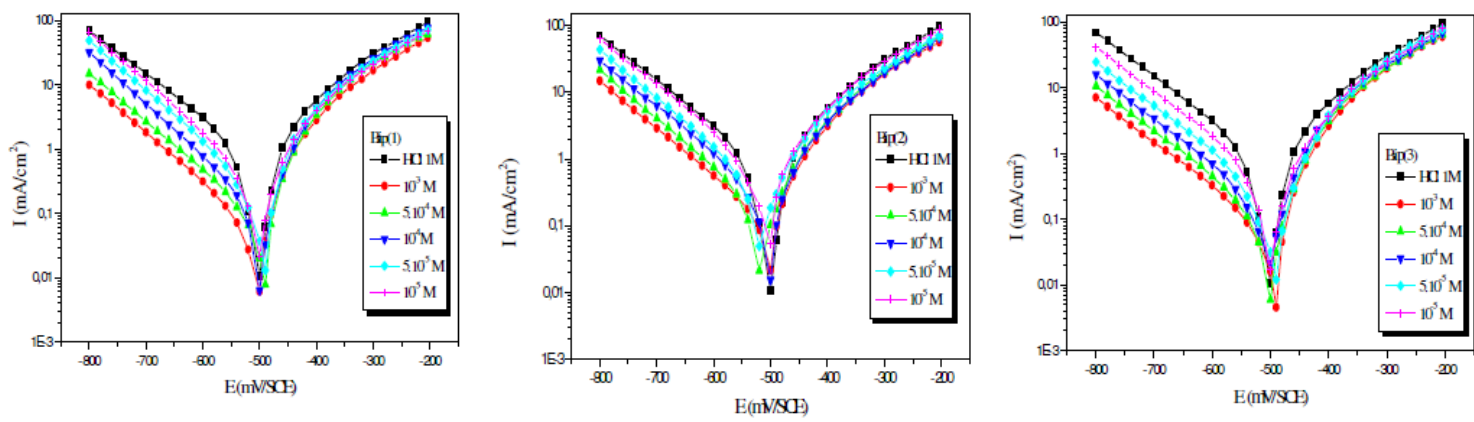

Figure 5. Potentiodynamic polarization curves for $\mathrm{C} 38$ steel in $1 \mathrm{M} \mathrm{HCl}$ containing different concentrations of Bip (1), Bip (2) and Bip (3) at $308 \mathrm{~K}$.

At first, when there is not enough Fe(inh) ads to cover the steel surface, owing to low concentration of the inhibitors or because the adsorption rate is slow, metal 
dissolution takes place at sites on the iron surface free of Fe(inh) ads. With a high inhibitor concentration, a compact and coherent inhibitor layers formed over the copper, which reduces chemical attacks on the metal $[2,40,77,78]$. The cathodic polarization curve may be attributed to the reduction reaction of $\mathrm{H}^{+}$at the metallic interface. The cathodic corrosion reaction (equation 9) in de-aerated acidic chloride solution may be expressed as:

$$
2 \mathrm{H}^{+}+2 e^{-} \rightarrow \mathrm{H}_{2}
$$

From Fig. 5 we can see that the addition of $\operatorname{Bip}(1)$, Bip(2) and $\operatorname{Bip}(3)$ inhibitors shifts the potential of the metal in the negative direction due to the decrease in the rate of the cathodic reaction $[4,79,80]$.

Corrosion parameters such as corrosion potential $\left(E_{\text {corr }}\right)$ and corrosion current density $\left(I_{\text {corr }}\right)$, in the presence of different concentrations of $\operatorname{Bip}(1), \operatorname{Bip}(2)$ and Bip(3) were calculated from the potentiodynamic polarization curves and tabulated in Table 5. The linear Tafel segments of anodic and cathodic curves were extrapolated to corrosion potential to obtain corrosion current densities $\left(I_{\text {corr }}\right)$. It is clear from Table 5 that the corrosion current densities $I_{\text {corr }}$ decrease with increasing the inhibitor concentration.

Table 5. Parameters obtained by Tafel polarization technique for steel in $1 \mathrm{M} \mathrm{HCl}$ solutions in the absence and presence of different inhibitors concentrations at $303 \mathrm{~K}$.

\begin{tabular}{|c|c|c|c|c|c|}
\hline inhibitors & $\begin{array}{c}\mathrm{C} \\
(\mathrm{M})\end{array}$ & $\begin{array}{c}\mathrm{E}_{\text {corr }} \\
(\mathrm{mV} / \mathrm{SCE})\end{array}$ & $\begin{array}{c}\beta_{\mathrm{c}} \\
(\mathrm{mV} / \mathrm{dec})\end{array}$ & $\begin{array}{c}\mathrm{I}_{\text {corr }} \\
\left(\mu \mathrm{A} / \mathrm{cm}^{2}\right)\end{array}$ & $\begin{array}{l}\mathrm{IE}_{\mathrm{I}-\mathrm{E}} \\
(\%)\end{array}$ \\
\hline Blanc & 1 & -502 & 147.9 & 912 & - \\
\hline \multirow{5}{*}{ Bip1 } & $10^{-5}$ & -499 & 132.1 & 366.8 & 60 \\
\hline & $5 \times 10^{-5}$ & -490 & 129.7 & 178.9 & 80 \\
\hline & $10^{-4}$ & -498 & 124.3 & 117.3 & 87 \\
\hline & $5 \times 10^{-4}$ & -495 & 133.1 & 80.1 & 91 \\
\hline & $10^{-3}$ & -500 & 134.9 & 70.2 & 92 \\
\hline \multirow{5}{*}{ Bip2 } & $10^{-5}$ & -498 & 146.6 & 559.8 & 39 \\
\hline & $5 \times 10^{-5}$ & -516 & 136 & 297.8 & 67 \\
\hline & $10^{-4}$ & -500 & 143.4 & 248.2 & 73 \\
\hline & $5 \times 10^{-4}$ & -513 & 132.8 & 163.4 & 82 \\
\hline & $10^{-3}$ & -501 & 138.5 & 124.9 & 86 \\
\hline \multirow{5}{*}{ Bip3 } & $10^{-5}$ & -498 & 144 & 287.5 & 68 \\
\hline & $5 \times 10^{-5}$ & -493 & 146 & 145.7 & 84 \\
\hline & $10^{-4}$ & -495 & 144 & 83.7 & 91 \\
\hline & $5 \times 10^{-4}$ & -497 & 145 & 65.5 & 93 \\
\hline & $10^{-3}$ & -492 & 144 & 48.1 & 95 \\
\hline
\end{tabular}

All concentrations of Bip (1), Bip (2) and Bip (3) do not affect significantly $\mathrm{E}_{\text {corr. }}$ It has been reported out that if the inhibition is due to the geometric blocking effect, the shift of corrosion potential will be negligible $\left(\Delta \mathrm{E}_{\text {corr }}\right.$ will be zero) as the inhibitor is added to the solution 88,22,81-83]. The inhibition for this system cannot be caused by the active sites blocking effect, but may be due in the main to the geometric blocking effect. Positive values of $\mathrm{IE}_{\mathrm{I}-\mathrm{E}} \%$ indicated corrosion inhibition, and negative values showed corrosion acceleration $[16,18,43,75,76]$. 
The parallel Tafel curves obtained indicate that hydrogen evolution reaction is activation controlled and the addition of Bip (1), Bip (2) and Bip (3) does not modify the mechanism of this process. Being weakly basic, Bip (1), Bip (2) and Bip (3), rapidly protonated in acid solutions, exist in their cationic form. Due to electrostatic attraction, the inhibitors are strongly adsorbed onto the electron-rich areas blocking the cathodic sites. This is in agreement with the increase of the cathodic effect over potential and shift of the steady corrosion potential to less noble direction in presence of inhibitors. Therefore it can also be said that these inhibitors act as cathodic inhibitors.

The addition of $\operatorname{Bip}(1), \operatorname{Bip}(2)$ and $\operatorname{Bip}(3)$ at different concentrations led to a decrease in the cathodic current densities, which was pronounced at $10^{-3} \mathrm{M}$; its $\mathrm{IE}_{\mathrm{I}-\mathrm{E}} \%$ value was maximum $91 \%, 89 \%$ and $95 \%$, respectively, for $\mathrm{Bip}(1)$, $\mathrm{Bip}(2)$ and Bip(3). From these data one can recognize distinctly higher inhibition of Bip (1), Bip (2) and Bip (3) for $10^{-3} \mathrm{~mol} \mathrm{~L}^{-1}$ concentration which is the optimum concentration ranking them as follows:

$$
\text { Bip (3) > Bip (1) > Bip (2). }
$$

\section{Electrochemical impedance spectroscopy measurements}

The representative Nyquist plots of $\mathrm{C} 38$ steel in $1 \mathrm{M} \mathrm{HCl}$ solution in the presence and absence of various concentrations of Bip (1), Bip (2) and Bip (3), are given in Fig. 6. Various parameters such as charge-transfer resistance (Rt), double layer capacitance $\left(\mathrm{C}_{\mathrm{dl}}\right)$ and $\mathrm{f}_{\max }$ were obtained from impedance measurements and are shown in Table 6.
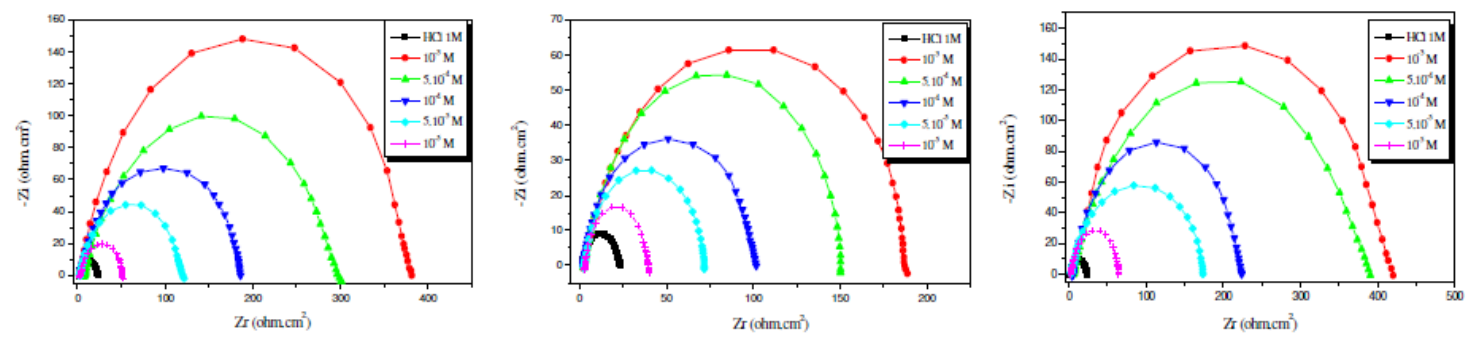

Figure 6. Nyquist plots of steel in $1 \mathrm{M} \mathrm{HCl}$ containing various concentrations of different inhibitors.

The impedance spectra exhibit one single depressed semicircle, and the diameter of the semicircle increases with the increase of the inhibitor concentration. The single semicircle indicates that the charge transfer takes place at the electrode/solution interface, the transfer process controls the corrosion reaction of steel and the presence of the inhibitor does not change the mechanism of steel dissolution [7-9,16-18,22,43]. The semicircles observed are depressed into the $\mathrm{Zr}$ (real axis) of Nyquist plot which is often referred to as frequency dispersion as a result of the no homogeneity or roughness of the metal surface [78,84-86] .

The fitted values are given in Table 6, showing that with increase in concentration of Bip (1), Bip (2) and Bip (3), Rt values increase prominently, while $C_{d l}$ values reduce. The values of $C_{d l}$ to Bip (1), Bip (2) and Bip (3), are superior to those obtained for the control medium. This increase can be attributed 
to hydration of the film due to absorption of the electrolyte in the film [16$18,22,43]$. The Rt values increased with the inhibitor concentrations, mainly suggesting the formation of a protective layer on the electrode surface. This layer makes a barrier for mass and charge-transfer [87,88]. Since Rt is inversely proportional to the corrosion rate, it can be used to calculate the inhibition efficiency.

As shown in the Fig. 6, the diameters of the spectres of impedance increase clearly with the increase of the inhibitor concentration in solution; all these diagrams were modelled by using the equivalent circuit presented on the Fig. 7. The results in Table 6 can be interpreted in terms of the equivalent circuit of the electric double layer shown in Fig. 7, which has been used previously to model the C38 steel - acid interface. This model is obtained using the ZView-software of modelling in order to determine the equivalent circuits from impedance data and Nyquist and Bode curves [48,89-95].

Table 6. Corrosion parameters obtained by impedance measurements for steel in $1 \mathrm{M}$ $\mathrm{HCl}$ at various concentrations of Bip (1), Bip (2) and Bip (3).

\begin{tabular}{|c|c|c|c|c|c|}
\hline inhibitors & $\mathrm{C}(\mathrm{M})$ & $\mathrm{R}_{\mathrm{t}}\left(\Omega \cdot \mathrm{cm}^{2}\right)$ & $\mathrm{f}_{\max }(\mathrm{Hz})$ & $\mathrm{C}_{\mathrm{dl}}\left(\mu \mathrm{F} / \mathrm{cm}^{2}\right)$ & $\mathrm{E}(\%)$ \\
\hline blank & 1 & 22.4 & 79.33 & 89.6 & - \\
\hline \multirow{5}{*}{ Bip1 } & $10^{-5}$ & 56.6 & 31.64 & 88.92 & 60 \\
\hline & $5 \times 10^{-5}$ & 125.1 & 15.82 & 80.45 & 82 \\
\hline & $10^{-4}$ & 180.2 & 12.5 & 70.69 & 88 \\
\hline & $5 \times 10^{-4}$ & 294.3 & 10 & 54.1 & 92 \\
\hline & $10^{-3}$ & 376.5 & 7.93 & 53.33 & 94 \\
\hline \multirow{5}{*}{ Bip2 } & $10-5$ & 39.0 & 50 & 81.66 & 43 \\
\hline & $5 \times 10-5$ & 72.6 & 31.64 & 69.32 & 69 \\
\hline & $10-4$ & 99.2 & 25 & 64.21 & 77 \\
\hline & $5 \times 10-4$ & 147.9 & 20 & 53.83 & 85 \\
\hline & $10-3$ & 190.5 & 15.8 & 52.9 & 88 \\
\hline \multirow{5}{*}{ Bip3 } & $10-5$ & 63.8 & 31.64 & 78.9 & 65 \\
\hline & $5 \times 10-5$ & 165.3 & 15.82 & 60.89 & 86 \\
\hline & $10-4$ & 226.7 & 12.5 & 56.19 & 90 \\
\hline & $5 \times 10-4$ & 395.4 & 7.93 & 50.78 & 94 \\
\hline & 10-3 & 432.2 & 7.93 & 46.46 & 95 \\
\hline
\end{tabular}

The transfer function can be represented by a resistance $R_{1}$ parallel to a capacitor $C$ and in series to them an additional resistance $R_{2}$, as expressed in equation (10):

$$
Z(\omega)=R_{2}+\left(\frac{1}{R_{1}}+j \omega C\right)^{-1}
$$

This transfer function is applicable to homogeneous systems with one time constant when the centre of the semicircle lies on the abscissa of the real part. It is evident that it cannot describe the observed depression of the capacitive loop and it is necessary to replace the capacitor by some element taking into account the frequency dispersion like the Constant Phase Element $(C P E)$. This element is a generalised tool, which can reflect the exponential distribution of the parameters of the electrochemical reaction related to energetic barrier at charge and mass transfer [91,92]. 


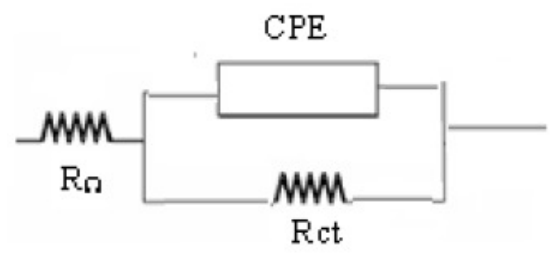

Figure 7. Suggested equivalent circuit model of the interface $\mathrm{C} 38$ steel/1 $\mathrm{M} \mathrm{HCl}$ (modelling by ZView-software).

Such phenomena often correspond to surface heterogeneity which may be the result of surface roughness, dislocations, distribution of the active sites or adsorption of inhibitors [25,32]. In order to fit and analyze the EIS data, the equivalent circuit shown in Fig. 6 is selected. This circuit is generally used to describe the iron/acid interface model $[21,91,92]$. In this equivalent circuit, $R t$ reflects the charge transfer resistance $R_{1}, R_{\Omega}$ is the resistance of the solution $R_{2}$, and $C P E$ is a constant phase element which replaces the pure capacitor. The impedance function of the $C P E$ is as follows (11):

$$
Z_{C P E}=Y^{-1}(j \omega)^{-n}
$$

$Y$ is the magnitude of the $C P E$ and $n$ an exponent related to the phase shift, both of them being frequency independent, and $\omega$ is the angular frequency. For whole numbers of $n=1,0,-1$, the $C P E$ is reduced to the classical lumped elements capacitor $(C)$, resistance $(R)$ and inductance $(L)$, respectively. The value of $n=$ 0.5 corresponds to the Warburg impedance $(W)$. Other values of $n$ approximately describe other types of frequency distribution behaviour of $C, R, L$ or $W$ with distributed parameters. In real iron/acid interface systems, the ideal capacitive behaviour is not observed due to roughness, or uneven current distributions on the electrode surface which results in frequency dispersion; therefore a $C P E$ is usually used instead of a capacitance $C_{d l}$ (double layer capacitance) to fit more accurately the impedance behaviour of the electrical double layer. The idealized capacitance $\left(C_{i d}\right)$ values can be described by the $C P E$ parameter values $Y$ and $n$ using the following expression (12) [21,96-98]:

$$
C_{i d}=\frac{Y \omega^{n-1}}{\sin (n \pi / 2)}
$$

\section{Adsorption isotherm and thermodynamic parameters}

Basic information on the interaction between inhibitors and metal surface can be provided using the adsorption isotherms. The adsorption of an organic adsorbate at a metal-solution interface can occur as a result of substitution adsorption process between the organic molecules presented in the aqueous solution $\left(\mathrm{Org}_{(\mathrm{sol})}\right)$, and the water molecules previously adsorbed on the metallic surface $\left(\mathrm{H}_{2} \mathrm{O}_{(\mathrm{ads})}\right)$ (equation 13) [20,40,99]:

$$
\mathrm{Org}_{(\mathrm{sol})}+\mathrm{nH}_{2} \mathrm{O}_{(\text {ads })} \rightarrow \mathrm{Org}_{(\text {ads })}+\mathrm{nH}_{2} \mathrm{O}_{(\text {sol })}
$$


where $\operatorname{Org}_{(\text {(sol) }}$ and $\operatorname{Org}_{(\mathrm{ads})}$ are the organic species in the bulk solution and adsorbed one on the metallic surface, respectively, $\mathrm{H}_{2} \mathrm{O}_{(\mathrm{ads})}$ is the water molecules adsorbed on the metallic surface and $n$ is the size ratio representing the number of water molecules replaced by one organic adsorbate. In order to obtain the adsorption isotherm, the degree of surface coverage, $\theta$, for different concentrations of inhibitor in $1.0 \mathrm{M} \mathrm{HCl}$ solutions has been evaluated by the following equation (14), where $w_{0}$ and $w_{\mathrm{i}}$ are the values of corrosion weight losses of C38 steel in uninhibited and inhibited solutions, respectively.

$$
\theta=1-\frac{w_{i}}{w_{0}}
$$

The $\theta$ values are calculated by the data of Table 3. According to the Langmuir's isotherm, the surface coverage $(\theta)$ is related to the inhibitor concentration $(C)$ by the following equation 15 , where $\mathrm{K}_{\mathrm{ads}}$ is the equilibrium constant of the inhibitor adsorption process $[8,74,100]$ :

$$
\frac{C_{i n h}}{\Theta}=\frac{1}{K_{a d s}}+C_{i n h}
$$

As seen from Fig. 8, the plot of $\mathrm{C}_{\text {inh }} / \theta$ versus $\mathrm{C}_{\text {inh }}$ yields a straight line with a correlation coefficient more than 0.9999, showing that the adsorption of these inhibitors in acidic solutions is fitted to Langmuir adsorption isotherm. These results show that the inhibition of $\mathrm{C} 38$-steel in $\mathrm{HCl}$ solutions by new synthesis compound derivatives is an adsorptive process (equation (13)). This isotherm assumes that the adsorbed molecules occupy only one site and that there are no interactions between the adsorbed species. The $\mathrm{K}_{\mathrm{ads}}$ values can be calculated from the intercept lines on the $\mathrm{C} / \theta$-axis. This value is also related to the standard free energy of adsorption $\left(\Delta \mathrm{G}_{\text {ads }}^{\circ}\right.$ ), by the following equation (16), where $\mathrm{K}_{\mathrm{ads}}$ is the adsorption equilibrium constant, $\Delta \mathrm{G}_{\text {ads }}^{\circ}$ is the standard free energy of adsorption, 55.5 is the concentration of water in the solution in mol dm${ }^{-3}, \mathrm{R}$ is the universal gas constant and $\mathrm{T}$ is the absolute temperature in Kelvin:

$$
\Delta G_{a d s}^{\circ}=-R T \operatorname{Ln}\left(55.5 K_{a d s}\right)
$$

The values of $\mathrm{K}_{\mathrm{ads}}$ and $\Delta \mathrm{G}_{\text {ads }}^{\circ}$ for $\operatorname{Bip}(1), \operatorname{Bip}(2)$ and $\operatorname{Bip}(3)$ in $1.0 \mathrm{M} \mathrm{HCl}$ solutions are given in Table 7 . The negative sign of $\Delta \mathrm{G}_{\text {ads }}^{\circ}$ indicates that the inhibitors are spontaneously adsorbed on the metal surface [3,4,14,101,102]. Generally, the magnitude of $\Delta \mathrm{G}_{\text {ads }}^{\circ}$ is around $-20 \mathrm{~kJ} \mathrm{~mol}^{-1}$ or less negative, suggesting that an electrostatic interaction exists between the inhibitor and the charged metal surface (i.e. physisorption). Standard free energy of adsorption $\left(\Delta \mathrm{G}_{\mathrm{ads}}^{\circ}\right)$ around $-40 \mathrm{~kJ} \mathrm{~mol}^{-1}$ or more negative indicates that a charge sharing or transferring from organic species to the metal surface occurs to form a coordinate type of bond (i.e. chemisorption) [68]. The calculated $\Delta \mathrm{G}_{\text {ads }}^{\circ}$ values for $\operatorname{Bip}(1)$, $\operatorname{Bip}(2)$ and $\operatorname{Bip}(3)$ in acid media show that an electrostatic interaction exists between the inhibitor and the charged metal surface while, as shown, chemisorption is more probable for $\operatorname{Bip}(1), \operatorname{Bip}(2)$ and $\operatorname{Bip}(3)$. It should be 
mentioned that the higher values of $\mathrm{K}_{\mathrm{ads}}$ and $\Delta \mathrm{G}_{\text {ads }}^{\circ}$ refer to a higher adsorptive and thus a higher inhibiting effect.

These results indicate also that the presence of the inhibitor increases the inhibition efficiency without change in adsorption mechanism. The extent of inhibition is directly related to the increase of the adsorption layer, which is a sensitive function of the molecular structure. Thermodynamically, $\Delta G_{\text {ads }}^{\text {o }}$ is related to the standard enthalpy and entropy of the adsorption process, $\Delta H_{\text {ads }}^{\circ}$ and $\Delta S_{\text {ads }}^{\text {o }}$, respectively, via equation (17) $[21,26,41]$ :

$$
\Delta G_{\mathrm{ads}}^{\mathrm{o}}=\Delta H_{\mathrm{ads}}^{\mathrm{o}}-T \Delta S_{\mathrm{ads}}^{\mathrm{o}}
$$
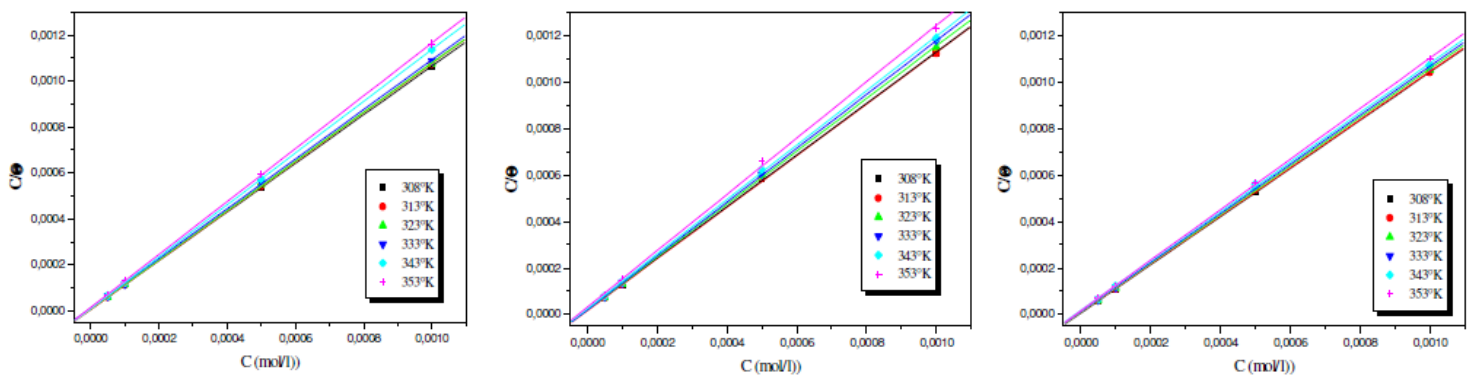

Figure 8. Langmuir adsorption plots for $\mathrm{C} 38$ steel in $1 \mathrm{M} \mathrm{HCl}$ containing different concentrations of inhibitor at different temperatures.

The standard enthalpy of adsorption $\left(\Delta H_{\mathrm{ads}}^{\mathrm{o}}\right.$ ) can be calculated according to the Van't Hoff equation (18):

$$
\ln K_{\mathrm{ads}}=-\frac{\Delta H_{\mathrm{ads}}^{\mathrm{o}}}{R T}+\text { constant }
$$

Inspection of the data in Table 7 , shows that the values of $\Delta \mathrm{H}^{\circ}$ ads by relation Van't Hoff, give the same results and their negative sign is usually characteristic of strong interaction and a highly efficient adsorption [7-9,16-18,22,43]. The obtained values of $\Delta G_{\text {ads }}^{\mathrm{o}}$ show the regular dependence of $\Delta G_{\text {ads }}^{\mathrm{o}}$ on temperature (Table 7 and Fig. 9), indicating a good correlation among thermodynamic parameters. However, a limited decrease in the absolute value of $\Delta G_{\text {ads }}^{o}$ with an increase in temperature it was observed. This behaviour is explained by the fact that the adsorption is somewhat unfavourable with increasing experimental temperature, indicating that the physisorption has the major contribution while the chemisorption has the minor contribution in the inhibition mechanism $[8,22,37,56,71,72]$.

The negative sign of $\Delta H_{\text {ads }}^{0}$ indicates that the adsorption of inhibitor molecules is an exothermic process. The value of $\Delta S_{\text {ads }}^{o}$ is negative, meaning that the $\operatorname{Bip}(1)$, $\operatorname{Bip}(2)$ and $\operatorname{Bip}(3)$ molecules move freely in the bulk solution (are chaotic) before adsorption, while as adsorption progresses, the inhibitor molecules adsorbed onto the C38 steel surface become more orderly, resulting in a decrease in entropy [7- 
$9,22,56,74,75]$. This order may more probably be explained by the possibility of formation of a steel-inhibitor film on the metal surface [37,71,72,78].

Table 7. Thermodynamic parameters for the adsorption of Bip (1), Bip (2) and Bip (3) in $1.0 \mathrm{M} \mathrm{HCl}$ on the $\mathrm{C} 38$ steel at different temperature.

\begin{tabular}{|c|c|c|c|c|c|c|c|}
\hline \multicolumn{2}{|c|}{$\mathrm{T}(\mathrm{K})$} & 308 & 313 & 323 & 333 & 343 & 353 \\
\hline \multirow{4}{*}{$\operatorname{Bip}(1)$} & $\mathrm{K}$ & 153493.12 & 168275.94 & 115764.46 & 83578.50 & 98609.60 & 67832.94 \\
\hline & $\begin{array}{c}\Delta \mathrm{G}_{\mathrm{ads}}^{\circ} \\
\left(\mathrm{kJ} \cdot \mathrm{mol}^{-1}\right)\end{array}$ & -40.89 & -41.80 & -42.13 & -42.53 & -44.28 & -44.47 \\
\hline & $\begin{array}{c}\Delta \mathrm{H}_{\mathrm{ads}}^{\circ} \\
\left(\mathrm{kJ}^{\mathrm{mol}} \mathrm{mol}^{-1}\right)\end{array}$ & \multicolumn{6}{|c|}{-16.85} \\
\hline & $\begin{array}{c}\Delta \mathrm{S}_{\mathrm{ads}}^{\circ} \\
\left(\mathrm{J} \cdot \mathrm{mol}^{-1} \cdot \mathrm{K}^{-1}\right)\end{array}$ & 78.05 & 79.71 & 78.27 & 77.12 & 79.97 & 78.24 \\
\hline \multirow{4}{*}{$\operatorname{Bip}(2)$} & $\mathrm{K}$ & 60121.81 & 47716.30 & 47187.39 & 49094.69 & 38562.69 & 31779.12 \\
\hline & $\begin{array}{c}\Delta \mathrm{G}_{\mathrm{ads}}^{\circ} \\
\left(\mathrm{kJ} \cdot \mathrm{mol}^{-1}\right)\end{array}$ & -38.49 & -38.51 & -39.71 & -41.05 & -41.59 & -42.24 \\
\hline & $\begin{array}{c}\Delta \mathrm{H}_{\mathrm{ads}}^{\circ} \\
\left(\mathrm{kJ} \cdot \mathrm{mol}^{-1}\right)\end{array}$ & \multicolumn{6}{|c|}{-10.30} \\
\hline & 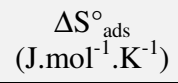 & 91.52 & 90.13 & 91.05 & 92.34 & 91.22 & 90.48 \\
\hline \multirow{4}{*}{$\operatorname{Bip}(1)$} & $\mathrm{K}$ & 160346.35 & 97993.10 & 87683.92 & 76435.65 & 55094.90 & 62201.43 \\
\hline & $\begin{array}{c}\Delta \mathrm{G}_{\text {ads }}^{\circ} \\
\left(\mathrm{kJ} \cdot \mathrm{mol}^{-1}\right)\end{array}$ & -41.00 & -40.38 & -41.37 & -42.28 & -42.61 & -44.21 \\
\hline & $\begin{array}{c}\Delta \mathrm{H}_{\mathrm{ads}}^{\circ} \\
\left(\mathrm{kJ} \cdot \mathrm{mol}^{-1}\right)\end{array}$ & \multicolumn{6}{|c|}{-17.87} \\
\hline & $\begin{array}{c}\Delta \mathrm{S}_{\mathrm{ads}}^{\circ} \\
\left(\mathrm{J} \cdot \mathrm{mol}^{-1} \cdot \mathrm{K}^{-1}\right)\end{array}$ & 75.09 & 71.92 & 72.75 & 73.30 & 72.13 & 74.62 \\
\hline
\end{tabular}
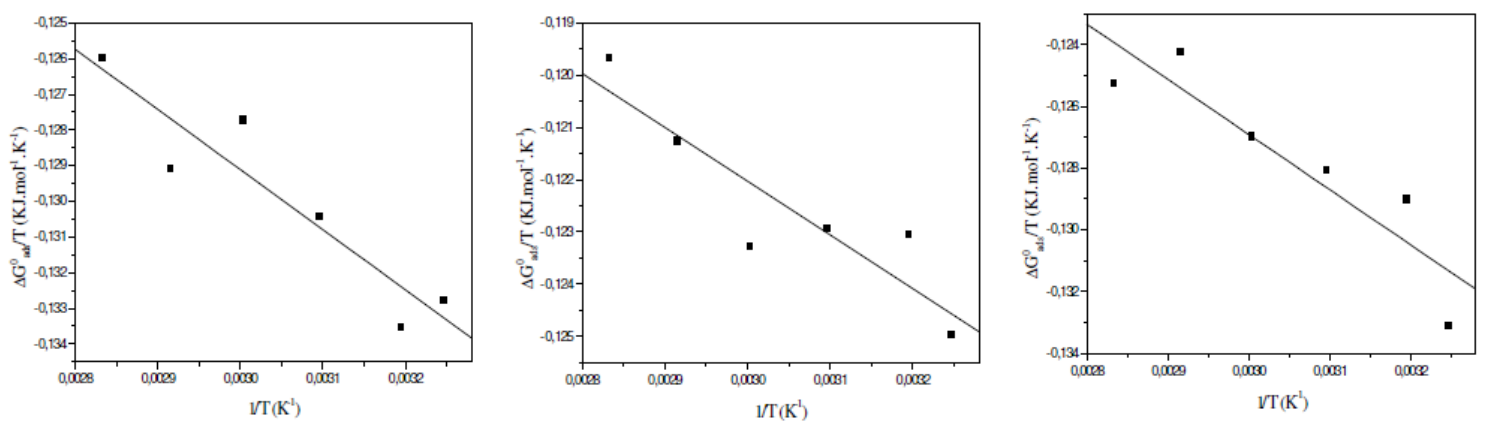

Figure 9. Relationship between $\Delta G_{a d s}^{0} / T$ and $1 / T$ of Bip (1), Bip (2) and Bip (3).

In the present study, chemisorption is evident from the apparent activation energy of the corrosion, that is, lower in presence of $\operatorname{Bip}(1), \operatorname{Bip}(2)$ and $\operatorname{Bip}(3)$, than in their absence, the inhibition efficiency, which is temperature independent and the large negative values of $\Delta G_{\text {ads }}^{0}$. Therefore, organic compounds may adsorb on a metal surface in the form of a neutral molecule via the chemisorption mechanism involving the sharing of electrons between the nitrogen atoms and iron. The covalent bond with the metal is most probably formed between the unpaired electrons of the $\mathrm{N}$-atom $[16,22,43]$. 


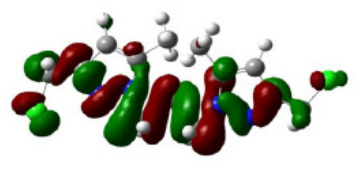

$\operatorname{Bip}(1)$ HOMO

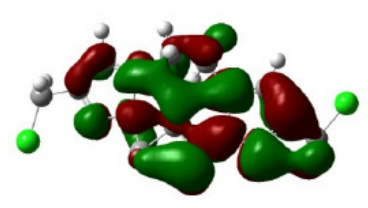

$\operatorname{Bip}(1)$ LUMO

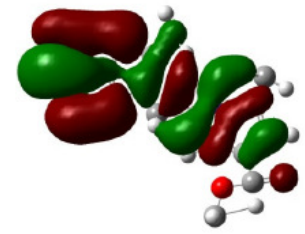

Bip(2) HOMO

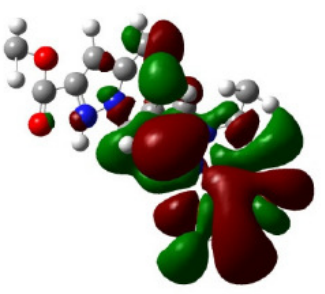

Bip(2) LUMO

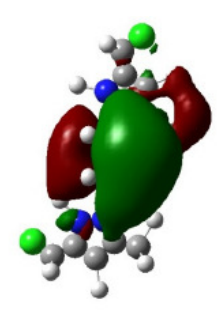

$\operatorname{Bip}(3)$ HOMO

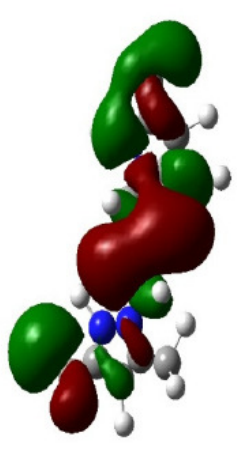

$\operatorname{Bip}(3)$ LUMO

Figure 10. The frontier molecule orbital density distributions of Bip (1), Bip (2) and Bip (3).

\section{Theoretical calculations}

Quantum chemical methods have already proven to be very useful in determining the molecular structure as well as elucidating the electronic structure and reactivity [59]. Thus, it has become a common practice to carry out quantum chemical calculations in corrosion inhibition studies. The predicted properties of reasonable accuracy can be obtained from density functional theory (DFT) calculations $[33,59,60]$. Some quantum chemical parameters, which influence the electronic interaction between surface atoms and inhibitor, are the energy of the highest occupied molecular orbital ( $\left.\mathrm{E}_{\mathrm{HOMO}}\right)$, the energy of the lowest unoccupied molecular orbital ( $\left.\mathrm{E}_{\mathrm{LUMO}}\right)$, the energy gap $\mathrm{E}_{\text {Hомо- }} \mathrm{E}_{\mathrm{LUMO}}(\Delta \mathrm{E})$, dipole moment $(\mu)$ and total energy (TE). All quantum chemical properties were obtained after geometric optimization with respect to all the nuclear coordinates using KohnSham approach at DFT level. The optimized structure of Bip(1), Bip(2) and Bip(3) compounds is shown in Fig. 10.

The computed quantum chemical properties such as energy of highest occupied molecular orbital ( $\mathrm{E}_{\text {Номо }}$ ), energy of lowest unoccupied molecular orbital $\left(\mathrm{E}_{\mathrm{LUMO}}\right)$, HOMO-LUMO energy gap $\left(\Delta \mathrm{E}_{\mathrm{H}-\mathrm{L}}\right)$ and dipole moment $(\mu)$ are summarized in the Table 8.

As $\mathrm{E}_{\text {номо }}$ is often associated with the electron donating ability of a molecule, high values of $\mathrm{E}_{\text {номо }}$ are likely to indicate a tendency of the molecule to donate electrons to the appropriate acceptor molecules with low-energy, empty molecular orbital. Increasing values of $\mathrm{E}_{\mathrm{HOMO}}$ facilitate adsorption (and therefore 
inhibition) by influencing the transport process through the adsorbed layer. Therefore, the energy of the $\mathrm{E}_{\mathrm{LUMO}}$ indicates the ability of the molecule to accept electrons; hence these are the acceptor states. An explanation based on the highest occupied molecular orbital, HOMO, the lowest unoccupied molecular orbital, LUMO, and the energy gap between them $\left(\Delta \mathrm{E}=\mathrm{E}_{\mathrm{HOMO}}-\mathrm{E}_{\mathrm{LUMO}}\right)$ : $\mathrm{E}_{\mathrm{HOMO}}$ is often associated with the electron-donating ability of molecules whereas the $\mathrm{E}_{\text {LUMO }}$ is associated with the electron accepting ability. Therefore, a high value of $\mathrm{E}_{\mathrm{HOMO}}$ indicates high tendency to donate electrons to the appropriate acceptor molecules with low empty molecular orbital energy. Likewise, a low value of $\mathrm{E}_{\text {LUMO }}$ indicates high tendency to accept electrons from the metal surface. Lower values of the energy difference $\Delta \mathrm{E}$ will cause higher inhibition efficiency because the energy to remove an electron from the last occupied orbital will be low $[10,54,60,73]$. On the other hand, the most widely used quantity to describe the polarity is the dipole moment of the molecule. Dipole moment is the measure of polarity of a polar covalent bond. It is defined as the product of charge on the atoms and the distance between the two bonded atoms. The total dipole moment, however, reflects only the global polarity of a molecule. For a complete molecule the total molecular dipole moment may be approximated as the vector sum of individual bond dipole moments. The theoretical study has shown that the dipole moment is well correlated with the inhibition efficiency (Fig. 3). Indeed, the inhibition efficiency increases with increasing the dipole moment. Effectively, for the dipole moment $(\mu)$, lower values of $\mu$ will favour accumulation of the inhibitor in the surface layer.

Table 8. Calculated quantum chemical parameters of the studied compounds.

\begin{tabular}{|c|c|c|c|}
\hline Quantum parameters & $\operatorname{Bip}(1)$ & $\operatorname{Bip}(2)$ & Вip(3) \\
\hline$E_{\text {Номо }}(\mathrm{eV})$ & -0.01214 & -0.00199 & -0.02768 \\
\hline$E_{\text {LUMO }}(\mathrm{eV})$ & 0.00380 & -0.03569 & 0.01065 \\
\hline$\Delta E$ gap $(\mathrm{eV})$ & 0.01594 & 0.03768 & 0.03833 \\
\hline$\mu$ (Debye) & 2.0933 & 4.6765 & 2.0178 \\
\hline
\end{tabular}

As we know, frontier orbital theory is useful in predicting the adsorption centres of the inhibitors responsible for the interaction with the surface metal atoms. The HOMO and the LUMO population of Bip (1), Bip (2) and Bip (3) were plotted and are shown in Fig. 10.

Analysis of this figure shows that the density of HOMO was distributed around the entire molecules. Moreover, the gap between the LUMO and HOMO energy levels of the molecule was another important factor that should be considered. It has been reported that excellent corrosion inhibitors are usually those organic compounds that do not only offer electrons to unoccupied orbital of the metal but also accept free electrons from the metal [58]. It is also well documented in literature that the higher the HOMO energy of the inhibitor, the greater its ability of offering electrons to unoccupied d-orbital of the metal, and the higher the corrosion inhibition efficiency.

It is evident from Table 8 that Bip (1), Bip (2) and Bip (3) are the highest $\mathrm{E}_{\mathrm{HOMO}}$ in the neutral form. This confirms the experimental results that interaction 
between different inhibitors and C38 steel is electrostatic in nature. Inhibition of corrosion is generally interpreted by adsorption of inhibitor molecules onto the metal surface. Two modes of adsorption can be envisaged. The physical adsorption requires the interaction of electrically charged metal surface and charged species in the bulk of the solution. Chemisorption mode implies charge sharing or charge transfer from the inhibitor molecule to the vacant orbital's of metal having low energy.

In this work, $\operatorname{Bip}(1), \operatorname{Bip}(2)$ and $\operatorname{Bip}(3)$ showed good inhibitory effect against corrosion of steel in $1 \mathrm{M} \mathrm{HCl}$. Bip(2) is considered more effective. The results obtained show that the compound Bip (3) has a higher $\Delta E g a p$. This parameter provides a measure for the stability of the formed film on the metal surface. The lower value of $\Delta E$ has, the higher stability is for the formed film.

Table 9. Theoretical calculation of the Mulliken atomic charges of Bip (1), Bip (2) and Bip (3) molecules.
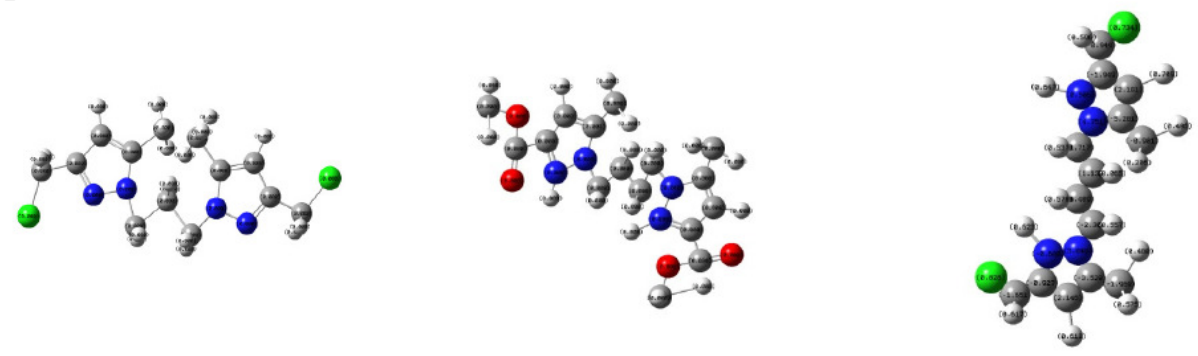

\begin{tabular}{|c|c|c|c|c|c|c|c|c|}
\hline $\mathrm{N}^{\circ}$ & Atoms & $\begin{array}{c}\text { Mulliken atomic } \\
\text { charges }\end{array}$ & $\mathrm{N}^{\circ}$ & Atoms & $\begin{array}{c}\text { Mulliken atomic } \\
\text { charges }\end{array}$ & $\mathrm{N}^{\circ}$ & Atoms & $\begin{array}{c}\text { Mulliken atomic } \\
\text { charges }\end{array}$ \\
\hline $\begin{array}{c}4 \\
5 \\
6 \\
7 \\
8 \\
9 \\
10 \\
11 \\
12 \\
13 \\
14 \\
15 \\
16 \\
17 \\
18 \\
19 \\
\end{array}$ & $\begin{array}{l}\text { N } \\
C \\
C \\
C \\
C \\
C \\
C \\
C \\
N \\
C \\
C \\
N \\
C \\
C \\
C \\
C \\
C\end{array}$ & $\begin{array}{c}-0.024202 \\
-0.150859 \\
-0.387850 \\
-0.426532 \\
-0.059855 \\
-0.148674 \\
-0.056892 \\
0.688218 \\
-0.399076 \\
-0.387579 \\
-0.025628 \\
-0.176542 \\
-0.126035 \\
-0.122840 \\
-0.045419 \\
-0.044987\end{array}$ & \begin{tabular}{c|}
1 \\
2 \\
3 \\
4 \\
6 \\
7 \\
9 \\
10 \\
12 \\
13 \\
16 \\
18 \\
19 \\
20 \\
22 \\
23 \\
25 \\
\end{tabular} & $\begin{array}{l}\text { C } \\
O \\
O \\
\text { C } \\
N \\
C \\
C \\
C \\
C \\
C \\
C \\
C \\
C \\
C \\
C \\
O \\
O \\
H\end{array}$ & $\begin{array}{l}-0.347557 \\
-0.489678 \\
-0.264730 \\
-0.663329 \\
-0.344503 \\
-0.275276 \\
-0.901873 \\
-1.673875 \\
-3.387410 \\
-1.851323 \\
-0.314697 \\
-0.851162 \\
-0.596585 \\
-0.789184 \\
-0.136692 \\
-0.001538 \\
-0.021302\end{array}$ & \begin{tabular}{|c|}
4 \\
5 \\
6 \\
7 \\
8 \\
9 \\
10 \\
11 \\
12 \\
15 \\
16 \\
18 \\
19 \\
20 \\
23 \\
24 \\
27 \\
28 \\
41 \\
42
\end{tabular} & $\begin{array}{l}\mathrm{C} \\
\mathrm{C} \\
\mathrm{C} \\
\mathrm{C} \\
\mathrm{C} \\
\mathrm{C} \\
\mathrm{C} \\
\mathrm{C} \\
\mathrm{C} \\
\mathrm{C} \\
\mathrm{C} \\
\mathrm{C} \\
\mathrm{C} \\
\mathrm{C} \\
\mathrm{H} \\
\mathrm{H} \\
\mathrm{H} \\
\mathrm{H} \\
\mathrm{H} \\
\mathrm{H}\end{array}$ & $\begin{array}{l}-0.541840 \\
-0.004378 \\
-0.638548 \\
-0.197689 \\
-0.258611 \\
-0.191338 \\
-0.634159 \\
-0.804929 \\
-0.326816 \\
-0.136847 \\
-0.719552 \\
-0.226937 \\
-0.413913 \\
-0.697467 \\
-0.113035 \\
-0.113035 \\
-0.084843 \\
-0.084843 \\
-0.166278 \\
-0.166278\end{array}$ \\
\hline
\end{tabular}

In addition, the lower the LUMO energy, the easier the acceptance of electrons from the metal surface, as the LUMO-HOMO energy gap decreased and the efficiency of inhibitor improved. It is clear from Table 8 that $\mathrm{E}_{\mathrm{LUMO}}$ of $\mathrm{Bip}(1)$, $\operatorname{Bip}(2)$ and $\operatorname{Bip}(3)$ exhibits the lowest, making the protonated form the most likely form for the interaction of steel with $\operatorname{Bip}(1)$, $\operatorname{Bip}(2)$ and $\operatorname{Bip}(3)$ molecules. Low values of the energy gap $(\Delta \mathrm{E})$ will provide good inhibition efficiencies, because the excitation energy to remove an electron from the last occupied orbital will be low. Lower values of dipole moment $(\mu)$ will favour accumulation of the inhibitor in the surface layer and therefore higher inhibition efficiency. The inhibition efficiency of the compounds depends on many major factors such as 
the number of adsorption active centres in the molecule and their charge density, molecule size, mode of adsorption, and formation of metallic film. The substitute effect on the steel inhibition of $\operatorname{Bip}(1), \operatorname{Bip}(2)$ and $\operatorname{Bip}(3)$ will be rationalized using global reactivity indexes, namely, Mulliken charge. The algebraic values of this quantity are given in Table $9[10,54,73]$.

\section{Conclusions}

$>$ Results obtained from the experimental and theoretical data show that Bip (1), Bip (2) and Bip (3) act as effective inhibitors of steel corrosion in $1 \mathrm{M} \mathrm{HCl}$.

The corrosion process was inhibited by adsorption of the organic compound on the metallic surface and obeys the Langmuir adsorption isotherm.

Inhibition efficiency increases with increase in the concentration of the Bip (1), Bip (2) and Bip (3) but remaining constant with rise in temperature.

$\rightarrow$ Polarisation measurements show that Bip (1), Bip (2) and Bip (3) act essentially as cathodic type inhibitors.

The inhibitor efficiencies determined by electrochemical polarisation, electrochemical impedance spectroscopy and by gravimetric methods are in good agreement.

Quantum chemical methods can conclude that the inhibitory efficiency depends on the structure and molecular of this inhibitors and the inhibition efficiency depends on many major factors such as the number of adsorption active centres in the molecule and their charge density, molecule size, mode of adsorption, and formation of metallic film

\section{References}

1. Afia L, Salghi R, Bammou L, et al. Acta Metallurgica Sinica-Engl Lett. 2012;25:10

2. Samide A, Tutunaru B, Negrila C, et al. Digest J Nanomater Biostruct. 2011;6:663.

3. Tebbji K, Aouniti A, Attayibat A, et al. Ind J Chem Tech. 2011;18:244.

4. Tebbji K, Oudda H, Hammouti, et al. Res Chem Intermediates. 2011;37:985.

5. Znini M, Bouklah M, Majidi L, et al. Int J Electrochem Sci. 2011;6:691.

6. Govindaraju KM, Gopi D, Kavitha L. J Appl Electrochem. 2009;39:2345.

7. Chetouani A, Hammouti B. Bull Electrochem. 2004;20:343.

8. Chetouani A, Hammouti B, Benhadda T, Daoudi M. Appl Surf Sci. 2005;249:375.

9. Chetouani A, Daoudi M, Hammouti B, et al. Corros Sci. 2006;48:2987.

10. Senhaji O, Taouil R, Skalli MK, et al. Int J Electrochem Sci. 2011;6:6290.

11. Thomas G, Hammouti N, Seitz A. J Shellfish Res. 2011;30:123.

12. Warad I, Azam M, Karama U, et al. J Molec Struct. 2011;1002:107.

13. Zarrouk A, Hammouti B, Touzani R, et al. Int J Electrochem Sci. 2011;6:4939. 
14. Zarrouk A, Hammouti $\mathrm{B}$, Zarrok $\mathrm{H}$ et al. Int $\mathrm{J}$ Electrochem Sci. 2011;6:6261.

15. Znini M, Majidi L, Laghchimi A, et al. Int J Electrochem Sci. 2011;6:5940.

16. Chetouani A, Hammouti B, Aouniti A, et al. Prog Org Coat. 2002;45:373.

17. Chetouani A, Hammouti B. Bull Electrochem. 2003;19:23.

18. Chetouani A, Aouniti A, Hammouti B, et al. Corros Sci. 2003;45:1675.

19. Zarrouk A, Warad I, Hammouti B, et al. Int J Electrochem Sci. 2010;5:1516.

20. Zerga B, Attayibat A, Sfaira M, et al. J Appl Electrochem. 2010;40:1575.

21. Bentiss F, Jama C, Mernari B, et al. Corros Sci. 2009;51:1628.

22. Chetouani C, Medjahed K, Sid-Lakhdar KE, et al. Corros Sci. 2004;46:2421.

23. Tadros AB, Abdelnabey BA. J Electroanal Chem. 1988;246:433.

24. Mernari B, H El Attari, M Traisnel, et al. Corros Sci. 1998;40:391.

25. Bentiss F, Lagrenee M, Traisnel M, et al. J Appl Electrochem. 1999;29:1073.

26. Lebrini M, Traisnel M, Lagrenee M, et al. Corros Sci. 2008;50:473.

27. Tang YM, Chen Y, Yang WZ, et al. J Appl Electrochem. 2008;38:1553.

28. Cisse MB, Zerga B, El Kalai F, et al. Surf Rev Lett. 2011;18:303.

29. Ai JZ, Guo XP, Qu JE, et al. Colloids Surf A-Physicochem Eng Asp. 2006;281:147.

30. Wahyuningrum D, Achmad S, Syah YM, et al. Int J Electrochem Sci. 2008;3:154.

31. Zarrouk A, Chelfi T, Dafali A, et al. Int J Electrochem Sci. 2010;5:696.

32. Kertit S, Hammouti B. Appl Surf Sci. 1996;93:59.

33. Mihit M, Laarej K, El Makarim HA, et al. Arab J Chem. 2010;3:55.

34. Moretti G, Quartarone G, Tassan A, Zingales A. Electrochim Acta. 1996;41:1971.

35. Khaled KF. Mater Chem Phys. 2008;112:290.

36. Truc TA, Hang TTX, Oanh VK, et al. Surf Coat Tech. 2008;202:4945.

37. Dudukcu M. Mater Corros-Werk Korros. 2011;62:264.

38. Afia L, Salghi R, Bazzi E, et al. Int J Electrochem Sci. 2011;6:5918.

39. Bammou L, Mihit M, Salghi R, et al. Int J Electrochem Sci. 2011;6:1454.

40. Benabdellah M, Yahyi A, Dafali A, et al. Arab J Chem. 2011;4:243.

41. Bouanis FZ, Jama C, Traisnel M, Bentiss F. Corros Sci. 2010;52:3180.

42. Herrag L, Hammouti B, Elkadiri S, et al. Corros Sci. 2010;52:3042.

43. Chetouani A, Medjahed K, Benabadji KE, et al. Prog Org Coat. 2003;46:312.

44. Tao JC, Wu YJ, Song JY. Polyhedron 1999;18:1015.

45. Acevedo-Pena P, Gonzalez I. J Electrochem Soc. 2012;159:C101.

46. Yadav R, Fedkiw PS. J Electrochem Soc. 2012;159:B340.

47. Yahia SAA, Hamadou L, Kadri A, et al. J Electrochem Soc. 2012;159:K83.

48. Larios-Duran ER, Antano-Lopez R. J Electroanal Chem. 2011;658:10.

49. Manjunatha H, Mahesh KC, Suresh GS, Venkatesha TV. Electrochim Acta. 2011;56:1439.

50. Umoren SA, Li Y, Wang FH. J Appl Electrochem. 2011;41:307. 
51. Virtanen S, Ives MB, Sproule GI, et al. Corros Sci. 1997;39:1897.

52. Bastos AC, Simoes AM, Gonzalez S, et al. Electrochem Comm. 2004;6:1212.

53. Dong TK, Kirchev A, Mattera F, et al. J Electrochem Soc. 2011;158:A326.

54. Laarej K, Bouachrine M, Radi S, et al. E-J Chem. 2010;7:419.

55. Barouni K, Bazzi L, Salghi R, et al. Mater Lett. 2008;62:3325.

56. Bouklah M, Attayibat A, Kertit S, et al. Appl Surf Sci. 2005;242:399.

57. Gao G, Liang CH. Electrochim Acta. 2007;52:4554.

58. Amin MA, Khaled KF, Mohsen Q, Arida HA. Corros Sci. 2010;52:1684.

59. Eddy NO, Awe FE, Gimba CE, et al. Int J Electrochem Sci. 2011;6:931.

60. Bouklah M, Harek H, Touzani R, et al. Arab J Chem. 2012;5:163.

61. Barouni K, Bazzi L, Albourine A. Ann Chim-Sci Mater. 2010;35:333.

62. Gece G, Bilgic S. Corros Sci. 2010;52:3435.

63. Gece G, Bilgic S, Turksen O. Mater Corros-Werk Korros. 2010;61:141.

64. Liu L, Li Y, Wang FH. J Mater Sci Tech. 2010;26:1.

65. Musa AY, Kadhum AAH, Mohamad AB, et al. J Central South Univ Tech. 2010;17:34.

66. Marichev VA. Electrochim Acta. 2008;53:6304.

67. Musa AY, Kadhum AAH, Mohamad AB, et al. Corros Sci. 2010;52:526.

68. Musa AY, Kadhum AAH, Takriff MS, et al. Corros Eng Sci Tech. 2010;45:163.

69. Pound BG. J Biomed Mater Res Part B-Appl Biomater. 2010;94B:287.

70. Ranjana, Banerjee R, Nandi MM. Ind J Chem Tech. 2010;17:176.

71. Doner A, Solmaz R, Ozcan M, Kardas G. Corros Sci. 2011;53:2902.

72. Doner A, Kardas G. Corros Sci. 2011;53:4223.

73. Mert BD, Mert ME, Kardas G, Yazici B. Corros Sci. 2011;53:4265.

74. Ouchrif A, Zegmout M, Hammouti B, et al. Prog Org Coat. 2005;53:292.

75. Zerfaoui M, Hammouti B, Oudda H, et al. Bull Electrochem. 2004;20:433.

76. Zerfaoui M, Oudda H, Hammouti B. et al.Prog Org Coat. 2004;51:134.

77. Vedalakshmi R, Gopaland KR, Palaniswamy N. Corros Eng Sci Tech. 2009;44:20.

78. Behpour M, Ghoreishi SM, Mohammadi N, Salavati-Niasari M. Corros Sci. 2011;53:3380.

79. Oguzie EE, Li Y, Wang FH. Electrochim Acta. 2007;53:909.

80. Fushimi K, Miyamoto K, Konno H. Electrochim Acta. 2010;55:7322.

81. El-Sayed AR. Denki Kagaku. 1998;66:176.

82. Kai W, Leu CJ, Wu YJ. Oxid Metals. 1998;50:89.

83. Kai W, Leu CT, Lee PY. Oxid Metals. 1996;46:185.

84. Shen CB, Wang SG, Yang HY, et al.Acta Phys-Chim Sinica. 2004;20:664.

85. Shen CB, Wang SG, Yang HY, et al. Corros Sci. 2006;48:1655.

86. Shen CB, Wang SG, Yang HY, et al. Electrochim Acta. 2007;52:3950.

87. Benabdellah M, Khaled KF, Hammouti B.,Mater Chem Phys. 2010;120:61.

88. Bouhrira K, Ouahiba F, Zerouali D, et al. E-J Chem. 2010;7:S35.

89. Harrington DA, van den Driessche P. Electrochim Acta. 2011;56:8005.

90. Nikonenko VV, Kozmai AE. Electrochim Acta. 2011;56:1262.

91. Norian KH. J Power Sources. 2011;196:5205. 
92. Norian KH. J Power Sources. 2011;196:7812.

93. Norian KH. J Power Sources. 2011;196:2360.

94. Rahimian SK, Rayman S, White RE. J Power Sources. 2011;196:8450.

95. Hu XS, Li SB, Peng H. J Power Sources. 2012;198:359.

96. Keles H, Keles M, Dehri I, Serindag O. Mater Chem Phys. 2008;112:173.

97. Harrington SP, Wang F, Devine TM. Electrochim Acta. 2010;55:4092.

98. Shen CB, Wang SG, Yang HY, Long K, Wang FH. Appl Surf Sci. 2006;253:2118.

99. Hluchan V, Wheeler BL, Hackerman N. Werk Korros-Mater Corros. 1988;39:512.

100. Morad MS. J Appl Electrochem. 2005;35:889.

101. Das C. Ind J Chem Tech. 1996;3:259.

102. Benabdellah M, Tounsi A, Khaled KF, Hammouti B. Arab J Chem. 4 (2011) 17. 